NBER WORKING PAPER SERIES

\title{
INVESTOR INATTENTION, FIRM REACTION, AND FRIDAY EARNINGS ANNOUNCEMENTS
}

\author{
Stefano DellaVigna \\ Joshua Pollet \\ Working Paper 11683 \\ http://www.nber.org/papers/w11683
}

\author{
NATIONAL BUREAU OF ECONOMIC RESEARCH \\ 1050 Massachusetts Avenue \\ Cambridge, MA 02138 \\ October 2005
}

An earlier version of the paper was distributed under the title "Strategic Release of Information on Friday: Evidence from Earnings Announcements". We thank John Campbell, David Card, Raj Chetty, Kent Daniel, Yonca Ertimur, John Graham, David Hirshleifer, Wei Jiang, Lawrence Katz, David Laibson, Owen Lamont, Ulrike Malmendier, Maria Nondorf, Allen Poteshman, Torsten Persson, Matthew Rabin, Jeremy Stein, XiaoJun Zhang, and audiences at Fuqua, the Hong Kong University of Science and Technology, Kellogg, IIES (Stockholm), London Business School, University College (London), UC Berkeley, UI Urbana-Champaign, University of Zurich, the Adam Smith Asset Pricing Conference (LBS), the AEA Meetings 2005, the Yale Conference on Behavioral Science, and SITE 2004 (Psychology and Economics) for valuable comments. Jessica Chan, Eric Fleekop, Richard Kim, Clarice Li, Ming Mai, Raymond Son, Matthew Stone, and Terry Yee helped collect the announcement dates from the newswires. Dan Acland and Saurabh Bhargava provided excellent research assistance. The views expressed herein are those of the author(s) and do not necessarily reflect the views of the National Bureau of Economic Research.

C2005 by Stefano DellaVigna and Joshua Pollet. All rights reserved. Short sections of text, not to exceed two paragraphs, may be quoted without explicit permission provided that full credit, including ( $)$ notice, is given to the source. 
Investor Inattention, Firm Reaction, and Friday Earnings Announcements

Stefano DellaVigna and Joshua Pollet

NBER Working Paper No. 11683

October 2005

JEL No. G1, G3, J0

\section{$\underline{\text { ABSTRACT }}$}

Do firms release news strategically in response to investor inattention? We consider news about earnings and analyze the response of returns to announcements on Friday and other weekdays. Friday announcements have less immediate and more delayed stock return response. The delayed response as a percentage of the total response is 60 percent on Friday and 40 percent on other weekdays. In addition, abnormal trading volume around announcement day is 10 percent lower for Friday announcements. These findings suggest that weekends distract investor attention temporarily. They support explanations of post-earning announcement drift based on underreaction to information caused by limited attention. We also document that firms release worse announcements on Friday. Friday announcements are associated with a 45 percent higher probability of a negative earnings surprise and a 50 basis points lower abnormal return. The firm-based evidence of strategic news release corroborates the investor-based evidence of inattention on Friday. The results for stock returns, volume, and strategic behavior support the hypothesis of limited attention.

Stefano DellaVigna

UC, Berkeley

Department of Economics

549 Evans Hall \#3880

Berkeley, CA 94720-3880

and NBER

sdellavi@berkeley.edu

Joshua Pollet

University of Illinois at Urbana Champaign

340 Wohlers Hall

1206 S. Sixth St.

Champaign, IL 61820

pollet@uiuc.edu 


\section{Introduction}

Consumers are bombarded with information regarding their personal and professional obligations. The cognitive capacities to process all of this information are limited. Limited cognitive capacities can explain, among other findings, the use of heuristics in cognitive decision-making (Gabaix et al., 2002) and underreaction to information (Huberman and Tomer, 2001). Despite the importance of limits to cognitive resources, little evidence exists on the extent to which the quality of decision-making declines in response to distractions.

We examine a decision where attention to new information plays a crucial role, the response to earnings surprises. We consider a regular event that is likely to distract investors from jobrelated tasks, the weekend. We compare the reaction to earnings surprises for announcements that occur just before the weekend, on Friday, to the reaction on other weekdays.

If weekends distract investors and lower the quality of decision-making, the immediate response to Friday earnings surprises should be less pronounced. As investors revisit their decisions in subsequent periods, the information should eventually be incorporated in stock prices. As a result, the delayed response, measured by the post-earnings announcement drift, should be of greater magnitude for Friday announcements.

This paper contributes to the debate regarding the causes of post-earnings announcement drift and momentum. Behavioral explanations for these anomalies depend on disposition effect (Grinblatt and Han, 2002; Frazzini, 2004), fluctuations in overconfidence (Daniel, Hirshleifer, and Subrahmanyam, 1998), beliefs about mean reversion (Barberis, Shleifer, and Vishny, 1998), or underreaction to information due to cognitive limits (Hong and Stein, 1999). Of these explanations, only underreaction to information makes the prediction that distractions increase the drift. Our paper, therefore, constitutes a novel test of the underreaction explanation.

We also consider the firm reaction to investor distraction. Managers that maximize shortterm value may exploit investor inattention by releasing negative announcements on Friday. The tendency to release bad news on Friday is allegedly common among firms and politicians. However, little evidence exists, because it is difficult to quantify good and bad news. We exploit the measurability of news quality for earnings announcements and document the extent of strategic release on Friday, controlling for other factors.

The paper proceeds as follows. In Section 2 we present a model of the response of stock prices to signals about earnings. In each period a share of the agents is distracted and does not observe a signal regarding company performance. Given limits to arbitrage in the form of risk aversion, the distracted agents affect prices. A larger share of inattentive investors shrinks the immediate response and magnifies the delayed response of prices to the signals. Distraction, therefore, increases the post-earnings announcement drift. The combined response to the announcement, however, is not affected by the distracted investors.

We also analyze the managerial decision to announce the signal on a low-distraction or high- 
distraction day. Companies that maximize the long-term share price do not have any incentive to strategically release information. Companies that maximize short-term share value, instead, adopt a simple threshold rule and release bad news on high-distraction days.

In the empirical section, we consider earnings announcements from January 1995 until June 2004. Since we analyze the difference between Friday and non-Friday announcements, the accuracy of the announcement date is critical. In Section 3 we devise a rule that identifies the correct announcement date from I/B/E/S and Compustat data with over 95 percent accuracy.

In Section 4, we evaluate the immediate, delayed, and long-term stock response to information by comparing the top and bottom quantile of the earnings surprise. The immediate stock response is 15 percent lower for Friday announcements than for non-Friday announcements. We find a similar attenuation using non-linear regressions for the whole sample. Conversely, the delayed response is 60 percent larger for Friday announcements. The combined long-term reaction is similar for Friday and non-Friday announcements.

We combine these findings in a summary measure. The delayed response as a percentage of the total response is 60 percent on Friday and 40 percent on other weekdays. The results are precisely estimated and are similar in the different specifications. The pattern is present for both positive and negative surprises, although the results are less precise for negative surprises.

These findings are consistent with weekend distractions. Individuals are more likely to underreact initially to Friday announcements. Eventually, investors become aware of the information they neglected and trade accordingly. The stronger delayed response reverses the initial underreaction induced by the distractions.

If investors are more distracted on Friday, we also expect lower abnormal trading volume for Friday announcements. In Section 5, we find that the abnormal volume is indeed 10 to 20 percent lower for Friday announcements than for non-Friday announcements. The results remain large and significant even after the introduction of controls and firm fixed effects.

The stock return and volume results suggest that investors exhibit a lower immediate response to Friday announcements. If firm managers wish to control the short-term response to earnings announcements, they should release worse announcements on Friday than on other weekdays. Indeed, in Section 6 we show that earnings announced on Friday are 25 percent more likely to be negative, and 45 percent more likely to fail to meet analyst expectations. Moreover, abnormal stock returns around announcement date are 50 basis points lower for Friday announcements. The evidence on the strategic release of bad news on Friday builds on Damodaran (1989). Damodaran documents worse earnings announcements and lower stock returns for Friday earnings (and dividend) announcements in the period 1981-1985. Compared to Damodaran (1989), we show that analysts are also disappointed by news released on Friday and that the results are robust to the introduction of company fixed effects and other controls. In addition, we provide an explanation for the release of negative news on Friday.

In Section 7 we consider alternative interpretations of the empirical findings regarding 
earnings announcements. First, the lower response to Friday announcements may be caused by the leakage of information before the official earnings announcements. However, the response of stock returns to earnings announcements in the 30 days before the announcement does not differ systematically for Friday and non-Friday announcements. Second, the lower initial response to Friday announcements could be due to systematic differences in the characteristics of companies announcing on Friday. While it is impossible to fully control for company heterogeneity, we show that the results are robust to the introduction of time, company, and market capitalization controls. In addition, we argue that heterogeneity is unlikely to simultaneously produce less immediate response and more delayed response for Friday announcements.

The results in this paper are related to the literature on inattention in finance (Barber and Odean, 2002; Barberis, Shleifer, and Vishny 1998; Daniel, Hirshleifer, and Subrahmanyam, 1998; DellaVigna and Pollet, 2005; Hong and Stein, 1999). From this standpoint, our key finding is that a distracting event increases the delayed reaction of stock prices to new information. This result supports the theory that momentum effects (Jegadeesh and Titman 1993) and post-earnings announcement drift (Chan, Jegadeesh, and Lakonishok, 1996; Bernard and Thomas, 1989) are caused by underreaction to new information due to cognitive constraints.

The evidence that firms schedule worse announcements on Friday expands the literature on earnings manipulation (Graham, Harvey, and Rajgopal, 2004). Firms manipulate accounting measures to achieve positive earnings or positive surprises (Degeorge, Patel, and Zeckhauser, 1999) and emphasize 'street' or GAAP earnings depending on which is more favorable (Dyck and Zingales, 2003; Hirshleifer and Teoh, 2003). In addition, firms release bad news later in the day (Patell and Wolfson, 1982) and later in the earnings season (Begley and Fischer, 1998).

Finally, this paper is an additional example of a market response to a bias. This is a long-standing theme in finance (Baker, Ruback, and Wurgler, forthcoming; DeLong et al., 1990; Shleifer, 2000) and it has more recently been applied to firm pricing (DellaVigna and Malmendier, 2004; Gabaix and Laibson, 2004) and political decision-making (Glaeser, 2005).

\section{Model}

We present a model of investment where some of the agents are distracted. All investors are exposed to a signal about next period's dividend, but only a fraction pay attention to the signal. All agents pay attention to the realized divided. The fraction of inattentive investors varies over time, for example depending on the day of the week of announcement. We use the noise trader framework of DeLong et. al. (1990) and allow managers to respond to investor inattention as in Hirshleifer and Teoh (2003). Unlike in this latter paper, however, managers cannot manipulate the signal. Instead, managers select the fraction of distracted investors by choosing the announcement date. 
Setup. The model is an overlapping generations framework, where the time interval for each period is best thought of as a quarter of a year. Investors make an investment decision at time $t$ and then consume all of their wealth at time $t+1$ after selling their assets to the next generation of investors. The timing for the model is as follows.

1. During period $t-1$ the risk associated with the dividend $D_{t}$ is resolved, and $D_{t}$ is paid at the end of period $t-1$.

2. Before the beginning of period $t$, the manager of the company decides to announce the signal $s_{t}$ on a day when the share of distracted investors is high or when it is low. This signal resolves some of the risk regarding the next dividend. The signal $s_{t}$ becomes public before the start of period $t$, but only the attentive investors observe it.

3. At the beginning of period $t$, all investors choose the amount of wealth to be invested in the risky asset and in the riskless asset. Attentive investors use the signal $s_{t}$ to make this portfolio decision, while the distracted investors do not. The equilibrium price $P_{t}$ is determined by aggregating demand for the risky asset across all investors.

4. After the equilibrium price is determined for period $t$ but before the start of period $t+1$, the risk regarding the dividend $\left(D_{t+1}\right)$ is resolved and $D_{t+1}$ is paid to both types of investors.

In the spirit of a Perfect Bayesian Equilibrium, we first solve for the optimal portfolio choice given the beliefs of the investors. We then investigate the optimal managerial policy conditioned on the decisions and beliefs of the investors. We verify that the investors' and manager's beliefs are correct in equilibrium.

Portfolio choice. At the beginning of quarter $t$, investor $i$ with a wealth $W_{t}^{i}$ makes a portfolio decision between a riskless asset and a risky asset. The riskless asset has a price of 1 and a gross return of $1+R$ every period. The risky asset has price $P_{t}$ and pays a risky dividend $D_{t+1}$ before the start of period $t+1$. Investor $i$ chooses the optimal investment of $\lambda_{t}^{i}$ units in the risky asset in order to maximize end-of-period wealth. Each investor has a quadratic utility function with risk aversion parameter $\gamma>0$. We define $E_{t}^{i}[$.$] as the expectation operator$ using the information available to individual $i$. The $i^{\text {th }}$ individual's maximization problem is

$$
\begin{gathered}
\max _{\lambda_{t}^{i}} E_{t}^{i}\left[W_{t+1}^{i}\right]-\frac{1}{2} \gamma \operatorname{Var}_{t}^{i}\left[W_{t+1}^{i}\right] \\
\text { s.t. } W_{t+1}^{i}=\lambda_{t}^{i}\left(P_{t+1}+D_{t+1}-P_{t}\right)+\left(W_{t}^{i}-\lambda_{t}^{i} P_{t}\right) R+W_{t}^{i} .
\end{gathered}
$$

Substituting the budget constraint into the maximization problem, we obtain the following solution for the demand $\lambda_{t}^{i}$ for the risky asset:

$$
\lambda_{t}^{i}=\frac{E_{t}^{i}\left[P_{t+1}+D_{t+1}\right]-P_{t}(1+R)}{\gamma \sigma_{i, t, P+D}^{2}},
$$


where $\sigma_{i, t, P+D}^{2} \equiv \operatorname{Var}_{t}^{i}\left(P_{t+1}+D_{t+1}\right)$. The demand for the risky asset depends positively on the investor's expectations of the future price $P_{t+1}$ and the future dividend $D_{t+1}$, and negatively on the current price $P_{t}$. Furthermore, the demand depends negatively on the risk aversion parameter $\gamma$ and the perceived variance of the risky asset, $\sigma_{i, t, P+D}^{2}$.

In order to complete the model, we need to specify the process for $D_{t+1}$, as well as the rules governing the expectations of the investors. We assume that the dividend $D_{t+1}$ incorporates both a signal (the earnings announcement) and an idiosyncratic realization. Formally, $D_{t+1}$ equals $\delta+s_{t}+\varepsilon_{t+1}$ where $s_{t} \sim N\left(0, \sigma_{s}^{2}\right)$ is the signal broadcast to the public about the upcoming dividend before the choice of $\lambda_{t}^{i}$. The term $\varepsilon_{t+1} \sim N\left(0, \sigma_{\varepsilon}^{2}\right)$ is the random component of dividends that is unknown until the end of period $t$. We assume that $s_{t}$ and $\varepsilon_{t}$ are contemporaneously independent and are drawn identically and independently across periods.

As for investor expectations, we assume that there is a continuum of investors on the interval $[0,1]$ where a fraction $1-\mu_{t}$ of investors observes the signal $s_{t}$ (attentive investors) and a fraction $\mu_{t}$ of investors does not (distracted investors). The manager chooses the share of distracted investors $\mu_{t}$ to be low $\left(\mu_{l}\right)$ or high $\left(\mu_{h}\right)$, with $0 \leq \mu_{l} \leq \mu_{h} \leq 1$. This feature of the model captures the idea that, within a quarter $t$, companies can release information on low-attention days - Friday - or high-attention days - other weekdays. We define $E_{t}^{\mu}[$.$] and$ $\sigma_{\mu, t,(.)}^{2}$ as the conditional expectation and variance operators for investors that do not observe the signal $(i \leq \mu)$. Similarly, we let $E_{t}^{1-\mu}[$.$] and \sigma_{1-\mu, t,(.)}^{2}$ be the conditional expectation and variance operators for investors that observe the signal $(i>\mu)$. The model nests the standard case with no distracted agents $\left(\mu_{l}=\mu_{h}=0\right)$. We define $E[$.$] and E_{t}[$.$] as the 'true' conditional$ and unconditional expectation operators, where $E_{t}[]=.E_{t}^{1-\mu}[$.$] by construction.$

At the beginning of time $t$, the attentive investors form their expectation of dividend using $s_{t}: E_{t}^{1-\mu}\left[D_{t+1}\right]=E_{t}\left[D_{t+1}\right]=\delta+s_{t}$. The distracted investors, instead, form an unconditional expectation of future dividends: $E_{t}^{\mu}\left[D_{t+1}\right]=E\left[D_{t+1}\right]=\delta$. Expectations about dividends two periods in the future do not depend on distraction in period $t$ : for any $k \geq 0$ and $v, w$ $\in\{\mu, 1-\mu\}, E_{t+k}^{v}\left[E_{t+k+1}^{w}\left[D_{t+k+2}\right]\right]=\delta$.

Equilibrium. In equilibrium, total demand for the risky asset must sum to 1 , or $\int_{0}^{1} \lambda_{t}^{i} d i=$ 1. After substituting for $\lambda_{t}^{i}$ in this expression, we solve for $P_{t}$ :

$$
P_{t}=\frac{b_{t} E_{t}^{\mu}\left[D_{t+1}+P_{t+1}\right]+\left(1-b_{t}\right) E_{t}^{1-\mu}\left[D_{t+1}+P_{t+1}\right]-a_{t}}{1+R}=\frac{\bar{E}_{t}\left[D_{t+1}\right]+\bar{E}_{t}\left[P_{t+1}\right]-a_{t}}{1+R}
$$

where $a_{t}=\left(\frac{\mu_{t}}{\gamma \sigma_{\mu, t, P+D}^{2}}+\frac{1-\mu_{t}}{\gamma \sigma_{1-\mu, t, P+D}^{2}}\right)^{-1}, \bar{E}_{t}=b_{t} E_{t}^{\mu}[]+.\left(1-b_{t}\right) E_{t}^{1-\mu}[$.$] and b_{t}=\frac{\mu_{t}}{\gamma \sigma_{\mu, t, P+D}^{2}} a_{t}$. The price of the asset is a weighted sum of the expectations for distracted and attentive investors, with weights given by $b_{t}$ and $1-b_{t}$, respectively. The weight $b_{t}$ itself is increasing in the fraction of distracted agents $\mu_{t}$, as shown in the Appendix. The risk premium $a_{t}$ is increasing in the risk aversion parameter $\gamma$. 
Recursively solving forward expression (2) and also imposing the relevant transversality condition $\lim _{T \rightarrow \infty}\left(\bar{E}_{t} \bar{E}_{t+1} \ldots \bar{E}_{t+T+1}\left[P_{t+T+2}\right]\right) /(1+R)^{T+2}=0$ yields

$$
P_{t}=\frac{\bar{E}_{t}\left[D_{t+1}\right]-a_{t}}{1+R}+\sum_{s=1}^{\infty} \frac{\bar{E}_{t} \bar{E}_{t+1} \ldots \bar{E}_{t+s}\left[D_{t+s+1}-a_{t+s}\right]}{(1+R)^{s+1}} .
$$

The price of the asset in period $t$ equals the expected payout in period $t+1$ (first term) plus the expected payout in the later periods (second term). Next, we analyze the expectations of $D_{t+s+1}$ and $a_{t+s}$ in the second term. Since the information available at time $t$ is uninformative regarding $D_{t+s+1}, \forall s>0$, we know that $\bar{E}_{t+1} \bar{E}_{t+2} \ldots \bar{E}_{t+s}\left[D_{t+s+1}\right]=\delta$. In principle, the risk premium $a_{t+s}$ depends on the managerial policy of information release, which itself depends on the realized signal. However, since future signals about dividends are unforecastable, the strategic release of future signals is unforecastable as well. Therefore, $E_{t+s-1}^{\mu}\left[a_{t+s}\right]=E_{t+s-1}^{1-\mu}\left[a_{t+s}\right]=\bar{a}$ where $\bar{a}=\eta a\left(\mu_{h}\right)+(1-\eta) a\left(\mu_{l}\right)$ and $\eta=\operatorname{prob}\left(\mu_{t+s}=\mu_{h}\right)^{1}$. Consequently, $\bar{E}_{t} \bar{E}_{t+1} \ldots \bar{E}_{t+s}\left[a_{t+s}\right]=\bar{a}$. It follows that

$$
P_{t}=\frac{\delta-\bar{a}}{R(1+R)}+\frac{\delta-a_{t}}{1+R}+\frac{1-b_{t}}{1+R} s_{t}
$$

The price $P_{t}$ equals the sum of three terms, the future discounted (risk-adjusted) dividend for all periods after the next, the average (risk-adjusted) dividend for period $t+1$, and the signal $s_{t}$ for period $t+1$. In the case of no distraction $\left(\mu_{t}=0\right.$ for all $\left.t\right), b_{t}$ equals 0 and expression (3) simplifies to $P_{t}=(\delta-\bar{a}) / R+s_{t} /(1+R)$. Hence, the sensitivity of $P_{t}$ to the signal $s_{t}$ equals $1 /(1+R)$. In the presence of distracted agents $\left(\mu_{t}>0\right), b_{t}$ is positive and the sensitivity $\partial P_{t} / \partial s_{t}$ is less than $1 /(1+R)$. Inattention makes prices less responsive to signals.

Given the expression for $P_{t}$ we can solve for $\sigma_{\mu, t, P+D}^{2}$ and $\sigma_{1-\mu, t, P+D}^{2}$. We obtain $\sigma_{\mu, t, P+D}^{2}=$ $(1+R)^{-2} \sigma_{(1-b) s-a}^{2}+\sigma_{s}^{2}+\sigma_{\varepsilon}^{2}$ and $\sigma_{1-\mu, t, P+D}^{2}=(1+R)^{-2} \sigma_{(1-b) s-a}^{2}+\sigma_{\varepsilon}^{2}$ where $\sigma_{(1-b) s-a}^{2}=$ $\operatorname{Var}\left[\left(1-b_{t}\right) s_{t}-a_{t}\right]$. The perceived variance is higher for the distracted investors, since they do not observe the signal $s_{t}$. In particular, the higher the variance of the signal $\left(\sigma_{s}^{2}\right)$, the larger the difference between $\sigma_{\mu, t, P+D}^{2}$ and $\sigma_{1-\mu, t, P+D}^{2}$. In the Appendix we show that the term $\sigma_{(1-b) s-a}^{2}$ is time-invariant, which implies that $\sigma_{\mu, t, P+D}^{2}$ and $\sigma_{1-\mu, t, P+D}^{2}$ are also time-invariant.

Response to signal. We now derive measures of the immediate and of the delayed response of the stock price to the signal $s_{t}$. These measures are the theoretical counterparts for the short-term response to an earnings announcement and post-earnings-announcement drift, respectively. Consider the return to the risky asset for two periods, from $t-1$ (before the signal $s_{t}$ is realized) to $t+1$ (after the dividend $D_{t+1}$ is paid). During the first period, the attentive agents learn the signal $s_{t}$, the equivalent of the earnings announcement. After the signal, trade takes place and the price $P_{t}$ is determined. Therefore, between $t-1$ and $t$ the

\footnotetext{
${ }^{1}$ We are assuming that the perceived variances are time-invariant. This condition is verified in the Appendix.
} 
immediate price reaction to the signal $s_{t}$ takes place. During the second period, from $t$ to $t+1$, the dividend $D_{t+1}$ is realized and trade takes place again. A delayed reaction to the signal $s_{t}$ may occur. Therefore, the total excess return from $t-1$ to $t+1$ can be decomposed into an immediate response - from $t-1$ to $t$ - and a delayed response - from $t$ to $t+1$. In Propositions 1 through 3 we analyze how these measures depend on the share of inattentive investors.

Define the dollar excess return from $t-1$ to $t$ as $Z_{t}=P_{t}+D_{t}-(1+R) P_{t-1}$. The abnormal return for the first period $(t-1$ to $t)$ is the difference between $E_{t}\left[Z_{t}\right]$ and $E_{t-1}\left[Z_{t}\right]$, that is, the change in expected returns due to new information. This abnormal return $E_{t}\left[Z_{t}\right]-E_{t-1}\left[Z_{t}\right]$ incorporates two sources of new information: the signal $s_{t}$ (regarding $D_{t+1}$ ) and the unexpected dividend $D_{t}-E_{t-1}\left[D_{t}\right]$. The second component is unrelated to the signal $s_{t}$ (by construction, $D_{t}$ is a function of $s_{t-1}$, not of $s_{t}$ ). Therefore, in order to focus on the response to the signal, we define the immediate response $E_{t}\left[I R_{t}\right] \equiv Z_{t}-E_{t-1}\left[Z_{t}\right]-\left(D_{t}-E_{t-1}\left[D_{t}\right]\right)$, the unexpected excess return minus the unexpected dividend. Define $\sigma_{b s}=\operatorname{Cov}\left(b_{t}, s_{t}\right)$.

Proposition 1.(i) The immediate response $E_{t}\left[I R_{t}\right]$ is given by

$$
E_{t}\left[I R_{t}\right]=\frac{\bar{a}-a_{t}}{1+R}+\frac{\sigma_{b s}}{1+R}+\frac{1-b_{t}}{1+R} s_{t}
$$

$E_{t}\left[I R_{t}\right]$ is a linear function of the signal $s_{t}$, with slope coefficient $\left(1-b_{t}\right) /(1+R)$. (ii) The coefficient $\left(1-b_{t}\right) /(1+R)$ is decreasing in the share of distracted investors $\mu_{t}$ and is equal to $1 /(1+R)$ if $\mu_{t}=0$.

The first two terms in expression (4) depend on the strategic behavior of the company manager (addressed below). The first term represents the unexpected fluctuation in the risk premium, while the second term reflects the covariance between the fraction of attentive investors and the signal. If the share of inattentive agents does not vary, making managerial behavior irrelevant, both terms vanish. The final term is the most relevant for the empirical Section. The abnormal return due to the announcement is a linear function of signal $s_{t}$ (conditional on the share of attentive agents at the time of release). The slope of this function, $\left(1-b_{t}\right) /(1+R)$, is decreasing in the share of distracted investors $\mu_{t}$. Inattentiveness reduces the immediate response of stock prices to the information contained in the signal.

The excess return for the second period $(t$ to $t+1)$ is $Z_{t+1}$. We measure the change in this expected return due to the realization of the signal $s_{t}$ (the announcement) as $E_{t}\left[D R_{t+1}\right] \equiv$ $E_{t}\left[Z_{t+1}\right]-E_{t-1}\left[Z_{t+1}\right]$. This measure captures the delayed response of stock prices to the signal $s_{t}$. Hence, it is the theoretical equivalent of the post-earnings announcement drift.

Proposition 2. (i) The delayed response $E_{t}\left[D R_{t+1}\right]$ is given by

$$
E_{t}\left[D R_{t+1}\right]=\left(a_{t}-\bar{a}\right)-\sigma_{b s}+b_{t} s_{t}
$$


$E_{t}\left[D R_{t+1}\right]$ is a linear function of the signal $s_{t}$, with slope coefficient $b_{t}$. (ii) The coefficient $b_{t}$ is increasing in the share of distracted investors $\mu_{t}$ and is equal to zero if $\mu_{t}=0$.

The first two terms in expression (5) closely parallel the corresponding terms in expression (4). They reflect fluctuations in attention and strategic managerial behavior. The last term captures the delayed response as a function of the signal. In particular, $E_{t}\left[D R_{t+1}\right]$ is a linear function of the signal $s_{t}$, conditional on the share of distracted agents at the time of release. The slope of the delayed reaction is increasing in the number of distracted investors and equals zero if all agents are attentive. Propositions 1 and 2 provide testable implications. A larger fraction of distracted agents leads to a lower immediate response and a greater delayed response.

We also consider the excess return during the two periods from $t-1$ to $t+1$, that is, $Z_{t+1, t-1} \equiv P_{t+1}+D_{t+1}+(1+R) D_{t}-(1+R)^{2} P_{t-1}$. We are interested in the change in this return due to the announcement of the signal $s_{t}$. As above, we remove the component due to the unexpected dividend $D_{t}$. Therefore, we define the (discounted) long-term response to the announcement as $E_{t}\left[L R_{t+1}\right] \equiv\left(E_{t}\left[Z_{t+1, t-1}\right]-E_{t-1}\left[Z_{t+1, t-1}\right]\right) /(1+R)-\left(D_{t}-E_{t-1}\left[D_{t}\right]\right)$.

Proposition 3. (i) The long-term response $E_{t}\left[L R_{t+1}\right]$ equals the discounted sum of the immediate response $E_{t}\left[I R_{t}\right]$ and of the delayed response $E_{t}\left[D R_{t+1}\right]$. (ii) $E_{t}\left[L R_{t+1}\right]$ is given by

$$
E_{t}\left[L R_{t+1}\right]=\frac{1}{1+R} s_{t} .
$$

$E_{t}\left[L R_{t+1}\right]$ is a linear function of the signal $s_{t}$, with slope coefficient $1 /(1+R)$. (iii) The coefficient $1 /(1+R)$ is independent of the share of distracted investors $\mu_{t}$.

The long-term response does not depend on the share of inattentive investors. The distracted investors slow the diffusion of information, but do not affect the cumulative response.

Finally, we consider a summary measure of the delay with which the news is incorporated in stock returns. Let $s_{A}$ and $s_{B}$ be signals of different quality where $s_{A}>s_{B}$. We define the delayed response ratio as the ratio of (differential) delayed response to the (differential) longterm response: $D R R_{t}=\left(E\left[D R_{t} \mid s_{A}, \mu_{t}\right]-E\left[D R_{t} \mid s_{B}, \mu_{t}\right]\right) /\left(E\left[L R_{t} \mid s_{A}, \mu_{t}\right]-E\left[L R_{t} \mid s_{B}, \mu_{t}\right]\right)$.

Corollary 1. The delayed response ratio $D R R_{t}$ is given by

$$
D R R_{t}=\frac{b_{t}}{1+R}
$$

and it satisfies $0 \leq D R R_{t} \leq 1 /(1+R)$. (ii) $D R R_{t}$ is increasing in the share of distracted investors $\mu_{t}$ and is equal to zero if $\mu_{t}=0$.

On high-distraction days (high $\mu_{t}$ ), a greater fraction of the long-term response is delayed. In the absence of distraction $\left(\mu_{t}=0\right)$, the delayed response ratio is zero. 
Manager optimization. The manager of the firm cannot manipulate the mean or variance of the signal $s_{t}$. However, the manager can announce the signal on a high-distraction $\left(\mu_{t}=\mu_{h}\right)$ or a low-distraction day $\left(\mu_{t}=\mu_{l}\right)$. We consider managers that decide the day of announcement each period. We allow these agents to maximize long-term value or short-term value. ${ }^{2}$ We also consider managers that commit ex ante to a simple announcement strategy.

Long-term managers maximize the expectation at time $t$ of prices at time $t+1$, that is, $E_{t}\left[P_{t+1}\right]$. Expression (3) for $P_{t+1}$ implies $E_{t}\left[P_{t+1}\right]=(\delta-\bar{a}) / R-\sigma_{b s} /(1+R)$, an expression that is independent of the decision to release at $\mu_{t}=\mu_{l}$ or at $\mu_{t}=\mu_{h}$. (This expression is identical for $E_{t}\left[P_{t+k}\right]$, with $k \geq 1$.) Since the expected long-term price is independent of the release decision, the manager is indifferent between $\mu_{t}=\mu_{l}$ and $\mu_{t}=\mu_{h}$.

Short-term managers maximize the current price $E_{t}\left[P_{t}\right]=P_{t}$. They solve the problem

$$
\max _{\mu_{t} \in\left\{\mu_{h}, \mu_{l}\right\}} \frac{\delta-\bar{a}}{R(1+R)}+\frac{\delta-a_{t}}{1+R}+\frac{1-b_{t}}{1+R} s_{t}
$$

subject to the definitions for $a_{t}$ and $b_{t}$. The manager faces a trade-off between two forces, captured in the last two terms of (7). First, a manager releasing a low signal $s_{t}$ prefers to release when distraction is high $\left(\mu_{t}=\mu_{h}\right.$ and $b_{t}$ high) so that fewer investors become aware of the signal (and vice versa for a high signal). Second, the decision to release on a highdistraction day increases the risk premium $a_{t}$ since a higher fraction of investors does not observe the signal. In the Appendix, we show that the trade-off between these forces leads to a threshold rule. Managers release on high-distraction days whenever the signal is sufficiently negative $\left(s_{t} \leq-\sigma_{s}^{2} \gamma\right)$. The threshold rule depends on risk aversion $\gamma$ and the variance of the signal $\sigma_{s}$. An increase in either of these two parameters increases the risk premium associated with release on high-distraction days, and therefore decreases the share of signals released on such days. The threshold rule implies that the average signal $s_{t}$ released on high-distraction days $\left(\mu_{t}=\mu_{h}\right)$ is worse than the average signal $s_{t}$ released on low-distraction days $\left(\mu_{t}=\mu_{l}\right)$. Similarly, the average immediate response $I R_{t}$ is lower on high-distraction days.

Managers that commit to a simple announcement strategy decide ex ante to always release the signal on a high-distraction day or on a low-distraction day. These managers maximize future expected price. Since the release strategy is independent of the signal, the expected price simplifies to $E_{t}\left[P_{t+1}\right]=\left(\delta-a_{j}\right) / R$, where $j=h$ or $l$. Given that $a_{j}$ is increasing in the fraction of distracted agents $\mu$, committed managers announce information on a low-distraction day in all periods. Proposition 4 summarizes the predictions regarding managerial behavior.

Proposition 4. (i) Managers that maximize long-term value are indifferent between $\mu_{l}$ and $\mu_{h}$. (ii) Managers that maximize short-term value choose $\mu_{t}=\mu_{h}$ whenever $s_{t} \leq-\sigma_{s}^{2} \gamma$. It fol-

\footnotetext{
${ }^{2}$ It is straightforward to show that managers that maximize a combination of long-term and short-term value behave like short-term value maximizers.
} 
lows that $E\left[s_{t} \mid \mu_{t}=\mu_{h}\right]<E\left[s_{t} \mid \mu_{t}=\mu_{l}\right]$ and $E\left[I R_{t} \mid \mu_{t}=\mu_{h}\right]<E\left[I R_{t} \mid \mu_{t}=\mu_{l}\right]$. (iii) Managers that commit to a simple announcement strategy always choose $\mu_{t}=\mu_{l}$.

Summary. On high-distraction days, stocks returns should display less initial response to announcements and more delayed response. The distracted investors should have no impact on the long-term response to announcements. The model also addresses the strategic release of information by managers. As long as some managers maximize short-term value, the signal quality should be lower on high-distraction days.

\section{$3 \quad$ Data and summary statistics}

Data. Our sources of earnings data are I/B/E/S and Compustat. We use the quarterly earnings announcements from I/B/E/S for which at least one analyst forms an earning forecast in the 30 days before the announcement. We restrict the sample to announcements that are reported in both I/B/E/S and Compustat with a difference of at most 5 calendar days between the reported announcement dates. We also require that stock return data be available in CRSP for these announcements. The resulting sample includes 202,933 quarterly announcements during the period from January 1984 to June 2004.

We construct a measure of the announcement date using the reported Compustat and $\mathrm{I} / \mathrm{B} / \mathrm{E} / \mathrm{S}$ dates. In order to quantify the accuracy of these dates, we randomly select 2,614 earnings announcements for the period 1984 to 2003 and use Lexis-Nexis to search the announcement date in the PR newswires. We take the newswire date to be the true date of announcement. We look for the function of the Compustat and I/B/E/S dates that matches the newswire date most accurately. We oversample announcements that occur on Friday according to I/B/E/S. The results of the search (available upon request) suggest that the optimal imputation rule for the date differs for three categories of announcements:

1. I/B/E/S and Compustat announcement dates differ. In the case of disagreement, the earlier date is usually the actual date of the announcement, and the later date is the date of publication in the Wall Street Journal. We impute the date to be the earlier one.

2. Before January 1, 1989: I/B/E/S and Compustat announcement dates agree. In this case, most announcements are recorded using the Wall Street Journal date in both data sets. We assign the announcement date to be the previous trading date.

3. After January 1, 1989: I/B/E/S and Compustat announcement dates agree. During this time period, the announcement date is usually from a newswire source. We impute the date to be the I/B/E/S and Compustat date.

After applying these rules, we measure the accuracy of the imputed announcement date (Appendix Table 1) for Friday and non-Friday announcements over three different time periods. 
In the period before 1989, the imputed date is correct for 65.6 percent of the non-Friday announcements and for 50.0 percent of the Friday announcements. Whenever the date is incorrect, the error is almost always of only one trading day. For the periods from 1989 to 1994, the pattern is similar, with higher accuracy rates. The accuracy is highest in the period from 1995 to 2004: the date is correct in 95.6 percent of the cases for Friday announcements and in 95.8 percent of the cases for non-Friday announcements.

This data suggests three patterns. First, before 1995 a substantial fraction of earnings announcements is recorded with error of one trading day. Second, the errors in recording are more common for Friday announcements than for non-Friday announcements, except in the later period. Third, the accuracy of the earning date has increased substantially, and is almost perfect after December 1994. For the purposes of this paper, even a one-day error in the reporting of the date is important, since it may lead to a misclassification of Friday announcements. In light of this evidence, we limit the analysis to the 127,099 earnings announcements taking place after 1994. In this period, the imputed earnings announcement date is almost always correct both for Friday and for non-Friday announcements.

As a measure of investor expectation, we use the consensus analyst forecast from I/B/E/S. The consensus forecast is defined as the median forecast among all the analysts that make a forecast in the last 30 calendar days before the earning announcement. If an analyst has made multiple forecasts in this time horizon, we use only the most recent one. ${ }^{3}$

We define the earnings surprise as the difference between the earnings announcement and the consensus earnings forecast, normalized by the price of a share (Kothari, 2001). Let $e_{t, k}$ be the earnings per share announced in quarter $t$ for company $k$ and $\hat{e}_{t, k}$ be the corresponding consensus analyst forecast ${ }^{4}$. Further, indicate by $P_{t, k}$ the price of the shares of company $k$ five trading days before the announcement in quarter $t$. The earnings surprise $s_{t, k}$ is

$$
s_{t, k}=\frac{e_{t, k}-\hat{e}_{t, k}}{P_{t, k}} .
$$

The price of a share $P_{t, k}$ is a renormalization factor. The earning surprise $s_{t, k}$ can be interpreted as the unexpected profits as a share of total market value of the company. For example, a value of $s_{t, k}^{1}=.01$ implies that the company earned an additional 1 percent of its market capitalization above the consensus estimate for profits.

We match the announcement dates with information on stock returns from CRSP. We also extract from CRSP measures of market capitalization and trading volume. We construct

\footnotetext{
${ }^{3}$ The results are similar if we use the average forecast as a measure of consensus forecast or if we use analyst forecasts over a shorter (15 days) horizon.

${ }^{4}$ The measure of earnings per share in I/B/E/S reflects capital structure changes. In order to make the units of the earning announcements and forecasts comparable with the units of the price data $P_{t, k}$, we apply the adjustment provided by $\mathrm{I} / \mathrm{B} / \mathrm{E} / \mathrm{S}$. Since the adjustment factor is stored as a truncated number, the resulting variables $e_{t, k}$ and $\hat{e}_{t, k}$ have fractional cents. We round the earning per share measure $e_{t, k}$ to the nearest cent and the earnings forecast $\hat{e}_{t, k}$ to the nearest half cent.
} 
cumulative abnormal returns for different windows of event time around the announcement date. Define $R_{\tau, k}$ the stock return of company $k$ on day $\tau$ and $R_{\tau, m}$ the market stock return on day $\tau$. We obtain $\hat{\beta}$ for company $k$ in quarter $t$ from the regression $R_{u, k}=\alpha_{t, k}+\beta_{t, k} R_{u, m}$ for days $u$ from $\tau-300$ to $\tau-46$, where $\tau$ is the date of the announcement in quarter $t$. The buy-and-hold abnormal return $R_{t, k}^{(h, H)}$ over time period $(\tau+h, \tau+H)$ for stock $k$ in quarter $t$ is then computed as $\left[\Pi_{j=\tau+h}^{\tau+H}\left(1+R_{j, k}\right)-1\right]-\hat{\beta}_{t, k}\left[\Pi_{j=\tau+h}^{\tau+H}\left(1+R_{j, m}\right)-1\right] .^{5}$

We drop observations with a missing earnings surprise (5,718 observations), or in which the earnings announcement $e_{t, k}$ or the earnings forecast $\hat{e}_{t, k}$ are larger in absolute value than the price of a share $P_{t, k}$ (173 observations). We also eliminate penny stocks (748 observations) as well as announcements on Saturday, Sunday, or holidays (228 observations). Finally, we exclude observations with returns in the top and bottom $1 / 10,000$ th of the distributions for $R_{t, k}^{(0,1)}$ or $R_{t, k}^{(2,75)}$ (50 observations). The final sample includes 121,381 observations.

Summary statistics. Earnings announcements in the final sample are distributed unevenly across weekdays (Table 1A). More than 80 percent of announcements occur on Tuesday, Wednesday, or Thursday, 14.0 percent occur on Monday and only 5.7 percent are on Friday. The model suggests a potential explanation for the small share of Friday announcements: firms that commit to an announcement schedule never announce on a low-attention day (Friday).

In Table 1B we present summary statistics for the whole sample (Column 1), for the 6,987 Friday announcements (Column 2), and for the 114,394 non-Friday announcements (Column $3)$. The average earning surprise $s_{t, k}$ is more negative for Friday announcements. Firms announcing on Friday also have 26 percent smaller market capitalization.

Friday announcements are more prevalent toward the beginning of the sample period. In general, 62.33 percent of announcements occur in the first month of the quarter (January, April, July, and October), 29.49 in the second month, and only 8.19 percent in the third month. Friday announcements are less likely to occur in the first month and more likely to occur in the second or third month.

We include measures of corporate governance for a subset of firms. To the extent that poor governance is correlated with short-term value maximization, we expect Friday announcements to be more likely for poorly-governed firms. Indeed, firms making Friday announcements are less likely to have a block-shareholder (Cremers and Nair, 2004), and more likely to have poor governance (Gompers et al., 2003), although the latter difference is not significant.

Finally, Columns 5 and 6 present the summary statistics for the subsample of companies with 10 to 90 percent of their announcements taking place on Friday. This criterion excludes companies that rarely announce earnings on Friday (97,381 observations) or that almost always announce earnings on Friday (178 observations), leaving a sample of 23,822 announcements. In this sample, the summary statistics for announcements on Friday (Column 5) and other week-

\footnotetext{
${ }^{5}$ The results in the paper are similar if we use raw returns or net returns.
} 
days (Column 6) are substantially closer. The controls for month and market capitalization are no longer significantly different, and the difference in the average year of announcement is reduced to less than three months. This subsample, labelled Homogeneous Sample, addresses to some extent the concern that companies announcing on Friday may have unobservable features that differ from companies announcing on other days.

\section{Stock return response}

In this Section, we examine the responsiveness of stock returns to earnings surprises at various horizons. We compare the responsiveness for announcements on Friday to the responsiveness for announcements on other weekdays. If the fraction of distracted investors is higher on Friday, there should be less immediate response to Friday announcements, followed by more delayed response (Propositions 1 and 2). The long-term response should be the same (Proposition 3). The fraction of the stock reaction occurring with delay should be higher for Friday announcements (Corollary 1). We present graphical evidence, followed by an analysis of top and bottom earnings quantiles including delayed response ratios, and by non-linear regressions.

\subsection{Graphical evidence}

To measure announcement quality ${ }^{6}$, we divide announcements into 11 bins, ordered by the earnings surprise $s_{t, k}$. Negative earning surprises are in Quantiles 1 through 5 , followed by zero surprises (Quantile 6), and positive surprises (Quantiles 7 though 11). The thresholds for the bins are set separately for each year to guarantee an equal number of non-Friday announcements for bins 1 through 5 and bins 7 through 11. Since positive surprises are twice as common as negative surprises, bins 7-11 have twice as many observations as bins 1-5. Within each bin, we separate the Friday announcements from the non-Friday announcements.

Panel E in Appendix Table 2 reports the average earnings surprise $s_{t, k}$ within each bin for the Friday and the non-Friday announcements. The within-quantile earnings surprise average is comparable for Friday and non-Friday announcements, except for the lowest bin. The average earnings surprise in the bottom quantile is -.049 , while it equals .015 in the top quantile. Between bins 3 and 10 the average earning surprise is smaller in absolute value than .006 .

Immediate response. In Figure 1a we display the immediate response of stock returns, $R_{t, k}^{(0,1)}$, to earnings surprises for Friday and non-Friday announcements. (Panel A in Appendix Table 2 reports the corresponding estimates). By construction, $R_{t, k}^{(0,1)}$ is the return from

\footnotetext{
${ }^{6}$ An alternative measure of announcement quality is the immediate stock return $R_{t, k}^{(0,1)}$. This investor-based measure has two drawbacks relative to the analyst-based measure that we employ. First, it does not allow for separate estimation of immediate and delayed response. Second, it is endogenously determined by inattention. For given level of the signal, a more extreme immediate stock response indicates that investors are less distracted.
} 
the close on the trading day before the earnings announcement to the close on the trading day after the earnings announcement for stock $k$ in quarter $t$. This measure captures the short-term response to announcements made during trading hours and announcements made after the market is closed. ${ }^{7}$ Compared to announcements on other days, the responsiveness of stock prices to earning surprises is substantially flatter for Friday announcements. Interestingly, most of the underreaction occurs for positive announcements: companies with positive announcements on Friday are significantly penalized initially. However, even for negative announcements there is less initial reaction on Friday: stock returns for quantiles 1 through 5 are less negative for Friday than for non-Friday announcements.

Delayed response. In Figure 1b we display the delayed reaction of stock returns, $R_{t, k}^{(2,75)}$, to the earnings announcements. In the non-Friday sample, positive earnings surprises are followed by positive returns in the period subsequent to the announcement, and the pattern is increasing in the magnitude of the surprise. Negative surprises are followed by negative delayed returns, but the magnitudes are smaller. In the Friday sample, the delayed response to positive surprises follows a similar pattern to the one in the non-Friday sample. In addition, there are large negative returns for the most negative surprises. Considering both positive and negative surprises, Friday announcements exhibit more delayed response.

Long-term response. In Figure 1c we display the total response of stock return, $R_{t, k}^{(0,75)}$, to earnings surprises. The response is similar for announcements on Friday and other weekdays.

\subsection{Top and bottom quantiles}

To quantify the graphical findings, we examine the stock response to very positive and to very negative earnings news. We measure the sensitivity to news as the difference in returns between the top and bottom quantiles of earnings surprises. We compare the immediate, delayed, and long-term sensitivity for Friday and non-Friday announcements. The OLS specification is

$$
R_{t, k}^{(h, H)}=\phi_{B}+\phi_{T-B} d_{t, k}^{t o p}+\phi_{B}^{F} d_{t, k}^{F}+\phi_{T-B}^{F} d_{t, k}^{t o p} d_{t, k}^{F}+\Gamma_{0} X_{t, k}+\Gamma_{1} d_{t, k}^{t o p} X_{t, k}+\varepsilon_{t, k}
$$

where $R_{t, k}^{(h, H)}$ denotes the abnormal stock returns for company $k$ in quarter $t$ between $h$ days before the announcement and $H$ days after the announcement. The sample includes only observations in the top quantile(s) $\left(d_{t, k}^{t o p}=1\right)$ or the bottom quantile(s) $\left(d_{t, k}^{t o p}=0\right)$. We focus on the coefficients $\phi_{T-B}$ and $\phi_{T-B}^{F}$. The coefficient $\phi_{T-B}$ measures the return to good news (top quantile) relative to bad news (bottom quantile) for non-Friday announcements. The coefficient $\phi_{T-B}^{F}$ captures the additional differential response for Friday relative to non-Friday announcements. Under the null hypothesis of constant (or no) investor distraction, $\phi_{T-B}^{F}$ should equal zero. Under the alternative hypothesis of higher distraction on Friday, $\phi_{T-B}^{F}$

\footnotetext{
${ }^{7}$ Since time stamp for the announcements is not available, we cannot separate announcements made during trading hours or after close.
} 
should be negative for the immediate response $\left(R_{t, k}^{(0,1)}\right)$ and positive for the delayed response $\left(R_{t, k}^{(2,75)}\right)$. Distracted investors react less to news early on and more later on.

Specification (9) includes a vector of controls $X_{t, k}$ that are also interacted with the earnings surprise indicator $d_{t, k}^{\text {top }}$. This specification allows the stock response to depend on a set of control variables. For example, the responsiveness of stocks to earnings news may be correlated with company size if profit shocks are more permanent for larger firms. Similarly, the responsiveness may have increased with time if earnings disclosure regulation decreased the pre-announcement leakage of information. We include indicators for year of announcement, as well as 10 step functions for market capitalization. The indicators for market capitalization are constructed from $\log \left(p_{t, k} n_{t, k}\right)-\sum_{k=1}^{K} \log \left(p_{t, k} n_{t, k}\right) / K$, that is, log market capitalization for company $k$ in quarter $t$ minus the average market capitalization for other companies making announcements in the same quarter. We also include month indicators to control for differences in return sensitivity across quarters and within a quarter (early versus late releases). Standard errors are clustered by day of announcement to control for correlation of returns on the same day.

Immediate response. Table $2 \mathrm{~A}$ presents specification (9) with the immediate stock return $R_{t, k}^{(0,1)}$ as dependent variable. Without controls (Column 1), the top-to-bottom average return for non-Friday announcements is 6.59 percent $\left(\hat{\phi}_{T-B}=.0659\right)$. Compared to this value, the top-to-bottom return for a Friday announcement is significantly smaller by 1.23 percentage points $\left(\hat{\phi}_{T-B}^{F}=-.0123\right)$, an 18.6 percent $\left(\hat{\phi}_{T-B}^{F} / \hat{\phi}_{T-B}=-.0123 / .0659\right)$ difference.

With controls (Column 2), the coefficient $\hat{\phi}_{T-B}$ (calculated at the average level of the controls) is similar to the estimate without controls. The top-minus-bottom return differential for Friday announcements is -.95 percent $\left(\hat{\phi}_{T-B}^{F}=-.0095\right)$, marginally significant, corresponding to a 13.9 percent $(-.0095 / .0682)$ effect. In Column 3 we present the results (with controls) for the Homogeneous Sample defined in Section 3. In this substantially smaller sample $(5,057$ observations), the coefficient $\phi_{T-B}^{F}$ is still negative $\left(\hat{\phi}_{T-B}^{F}=-.0055\right)$, but not significant.

In Columns 4, 5, and 6 of Table $2 \mathrm{~A}$ we replicate specification (9) on the observations in the top 2 and bottom 2 quantiles. (The variable $d_{t, k}^{\text {top }}$ is now an indicator for the top 2 quantiles.) The larger sample increases substantially the precision of the estimates. The top-to-bottom return differential for non-Friday announcements is 5.78 percent $\left(\hat{\phi}_{T-B}=.0578\right)$. Relative to this differential, Friday announcements are associated with a 18.8 percent $(0.0109 / 0.0578)$ lower immediate return response, an economically and statistically significant difference. After the introduction of controls (Column 5), the Friday top-to-bottom return differential is still significant $\left(\hat{\phi}_{T-B}^{F}=-.0087\right)$. In the Homogeneous Sample (Column 6), the $\hat{\phi}_{T-B}^{F}$ coefficient is still negative $\left(\hat{\phi}_{T-B}^{F}=-.0062\right)$, but not significant.

Delayed response. In Table $2 \mathrm{~B}$ we estimate specification (9) with the delayed abnormal stock performance $R_{t, k}^{(2,75)}$ as dependent variable ${ }^{8}$. In this specification, the coefficient $\phi_{T-B}$ is a measure of the post-earnings-announcement drift for non-Friday announcements. In the

\footnotetext{
${ }^{8}$ The results are similar if we use alternative horizons such as $(2,60)$, or $(2,90)$. The advantage of adopting
} 
sample with no controls (Column 1), the estimated drift $\hat{\phi}_{T-B}$ for non-Friday announcements equals 5.50 percent, a substantial amount consistent with previous estimates (Bernard and Thomas, 1990). For Friday announcements, the drift is significantly bigger by 3.80 percentage points $\left(\hat{\phi}_{T-B}^{F}=.0380\right)$. As a share of the non-Friday drift, the delayed response on Friday is 69 percent larger $\left(\hat{\phi}_{T-B}^{F} / \hat{\phi}_{T-B}=.0380 / .0550\right)$. After controlling for year, month, and market capitalization indicators (Column 2), the coefficient $\hat{\phi}_{T-B}^{F}$ is .0327 , marginally significant. In the Homogeneous Sample (Column 3), the drift is 5.27 percentage points larger on Friday $\left(\hat{\phi}_{T-B}^{F}=.0527\right)$, a significant difference. In this sample, the Friday drift is 124.6 percent $(.0527 / .0423)$ larger than on other weekdays.

For announcements in the top 2 and bottom 2 quantiles (Column 4), the drift for Friday announcements is 57 percent larger $\left(\hat{\phi}_{T-B}^{F} / \hat{\phi}_{T-B}=.0261 / .0455\right)$, a significant difference. The estimates for this sample resemble the estimates obtained using only the extreme quantiles. The Friday differential drift becomes marginally significant after introducing controls (Column 5). In the Homogeneous Sample (Column 6), the differential Friday drift is significant $\left(\hat{\phi}_{T-B}^{F}=\right.$ .0307) and larger than in the baseline sample (Columns 4 and 5).

Long-term response. In Table $2 \mathrm{C}$ we measure the difference in long-term returns $R_{t, k}^{(0,75)}$ between the top 1 (or 2) quantiles and the bottom 1 (or 2) quantiles of the earnings surprise. For the six specifications used in Tables $2 \mathrm{~A}$ and $2 \mathrm{~B}$, the top-bottom return differential on nonFridays varies from 12.56 percent $\left(\hat{\phi}_{T-B}=.1256\right.$, Column 1$)$ to 9.40 percent $\left(\hat{\phi}_{T-B}=.0940\right.$, Column 6). For these same specifications, the top-to-bottom differential response on Fridays $\hat{\phi}_{T-B}^{F}$ is positive, but not significantly so (except for a marginal significance in Column 3). Long-term stock returns are similar for Friday and non-Friday announcements.

Summary. Stock prices respond less to Friday earnings surprises than to non-Friday earnings surprises in the immediate period $(0,1)$, though this effect is not significant in the Homogeneous Sample. In the later period $(2,75)$, stock prices respond more to Friday earning surprises. Summing these two effects in the event window $(0,75)$, there is no significant differential long-term effect of Friday announcements. These patterns are consistent with the predictions of the model if more investors are inattentive to the information released on Friday. For Friday announcements, inattention leads to less initial response, followed by more delayed response, as investors become aware of the neglected information.

\subsection{Delayed response ratio}

We implement a unified test of the model, suggested by Corollary $1^{9}$. We compute the share of the total stock response to announcements $\left(R_{t, k}^{(0,75)}\right)$ that occurs with delay $\left(R_{t, k}^{(2,75)}\right)$. We then test whether the delayed response ratio (DRR) is higher for Friday announcements. There

$(2,75)$ is that it is the shortest horizon that typically includes the next earnings announcement.

${ }^{9}$ We thank Owen Lamont for suggesting this approach. 
are two advantages of this methodology: (i) it controls for any heterogeneity in the longterm reaction for Friday and non-Friday announcements by renormalizing with the long-term reaction; (ii) it offers an easily interpretable measure of the delay.

In Table 2D, we compute numerator and denominator of DRR as the difference in average returns between announcements in the top and bottom quantile, as in Section 4.2. The measure for non-Friday announcements is

$$
D R R=\frac{E\left[R_{k, t}^{(2,75)} \mid d_{t, k}^{t o p}=1, d_{t, k}^{F}=0\right]-E\left[R_{k, t}^{(2,75)} \mid d_{t, k}^{t o p}=0, d_{t, k}^{F}=0\right]}{E\left[R_{k, t}^{(0,75)} \mid d_{t, k}^{t o p}=1, d_{t, k}^{F}=0\right]-E\left[R_{k, t}^{(0,75)} \mid d_{t, k}^{t o p}=0, d_{t, k}^{F}=0\right]}=\frac{\phi_{T-B}^{(2,75)}}{\phi_{T-B}^{(0,75)}}
$$

where $\phi_{T-B}^{(2,75)}$ is the coefficient $\phi_{T-B}$ estimated in (9) with $R_{k, t}^{(2,75)}$ as dependent variable (and similarly for $\phi_{T-B}^{(0,75)}$ ) (Tables $2 \mathrm{~B}$ and $2 \mathrm{C}$ ). The standard errors for DRR are derived using the Delta method. In the benchmark specification without controls (Column 1), 43.80 percent of the top-to-bottom stock response is delayed. The results are remarkably similar with controls (Column 2) ${ }^{10}$, in the Homogeneous Sample (Column 3), and using the top 2 and bottom 2 quantiles (Columns 4 through 6). For these different specifications, the average delayed response ratio consistently lies between .40 and .44 .

Similarly, we compute the delayed response ratio for Friday announcements:

$$
D R R^{F}=\frac{E\left[R_{k, t}^{(2,75)} \mid d_{t, k}^{t o p}=1, d_{t, k}^{F}=1\right]-E\left[R_{k, t}^{(2,75)} \mid d_{t, k}^{t o p}=0, d_{t, k}^{F}=1\right]}{E\left[R_{k, t}^{(0,75)} \mid d_{t, k}^{t o p}=1, d_{t, k}^{F}=1\right]-E\left[R_{k, t}^{(0,75)} \mid d_{t, k}^{t o p}=0, d_{t, k}^{F}=1\right]}=\frac{\phi_{T-B}^{(2,75)}+\phi_{T-B}^{F(2,75)}}{\phi_{T-B}^{(0,75)}+\phi_{T-B}^{F(2,75)}}
$$

In the benchmark specification (Column 1), 62.87 percent of the top-to-bottom response on Friday occurs with delay $\left(D R R^{F}=.6287\right)$. Compared to the delayed response ratio of .4380 on other weekdays, Fridays have an additional 19 percentage points of delayed reaction, an economically and statistically significant difference. The introduction of controls (Column 2), the estimation using the Homogeneous Sample (Column 3), and using the top 2 and bottom 2 quantiles (Columns 4 through 6) has little effect on the results.

The delayed response ratios (10) and (11) are computed using the difference in returns between the top and bottom quantiles. We now consider whether the findings depend more on the response to positive announcements (top quantile) or negative announcements (bottom quantile). We compute the delayed response ratio separately for quantile $j$, with $j=1,2,10,11$ (Figure 2a). The numerator and denominator of $D R R$ are estimated using the difference between expected returns in quantile $j$ and expected returns in quantile 6 .

For non-Friday announcements, the delayed response ratio is substantially smaller for negative announcements (.25 and .06) than for positive announcements (.54 and .53). There is more evidence of underreaction for positive than for negative announcements. Friday announcements have higher delay ratios, except in quantile 2. At the very bottom, the ratio for Friday (.54)

\footnotetext{
${ }^{10}$ In the specifications with controls, we estimate the effect at the average value of the controls.
} 
is more than twice as large as for non-Fridays (.25). At the top, the delayed response ratio is 15 to 20 percentage points larger on Friday, a difference that is significant in quantiles 10 and 11. The results are similar with controls and in the Homogeneous Sample (results not shown).

Summary. For non-Friday announcements, 40 to 44 percent of the stock response is delayed. For Friday announcements, this figure is 56 to 64 percent. The substantially higher delayed response ratio for Friday announcements is consistent with increased distraction postponing investor response on Friday. This pattern is observable both for positive and for negative surprises, although the results are less precise for negative surprises.

\subsection{Non-linear regressions}

In the OLS regressions above, we have restricted the attention to very positive and very negative earnings news. While this approach is simple and non-parametric, it does not take advantage of all available information. In order to use all the data, we impose identification restrictions on the relationship between earnings surprises and stock returns. We focus this Section on the immediate stock response $R_{t, k}^{(0,1)}{ }^{11}$

While the return $R_{t, k}^{(0,1)}$ is approximately a linear function of the surprise quantiles (Figure 1a), it is not a linear function of the earnings surprise $s_{t, k}$. Figure $2 \mathrm{~b}$ plots the average return

$R_{t, k}^{(0,1)}$ as a function of the average earnings surprise $s_{t, k}$ by quantile. The relationship between returns and surprises is monotonic but highly non-linear, with a clear S-shape (Kothari, 2001). The responsiveness of stocks to earnings surprises declines the larger the absolute value of the earning surprise. This observed non-linearity is consistent with the model in Section 2 if the measurement error of the earnings surprise is increasing in the magnitude of the observed surprise or if the cashflow news embedded in large earnings surprises is less persistent.

A second feature of Figure $2 \mathrm{~b}$ is that the sensitivity to announcements on Friday is approximately proportional to the sensitivity on other days. Given these two features, we impose a proportionality restriction, while allowing for a non-linear shape of returns to earnings announcements. We estimate the non-linear regression:

$$
R_{t, k}^{(0,1)}=\left(\alpha_{6}+\sum_{j \neq 6} \alpha_{j} d_{t, k}^{j}\right) *\left(1+\phi^{F} d_{t, k}^{F}\right) * \prod_{c}\left(1+\Gamma_{c} X_{t, k}^{c}\right)+\varepsilon_{t, k},
$$

The coefficients $\alpha_{j}$ capture the average immediate stock return for non-Friday announcements in quantile $j\left(d_{t, k}^{j}=1\right)$ relative to quantile 6 (no surprise). The coefficients $\alpha_{j}+\alpha_{6}$, therefore, correspond to the average returns by quantile presented in Figure 1a. The coefficient $\phi_{F}$ is the proportional increase (or decrease) in the return responsiveness for Friday vs. non-Friday announcements. Finally, we impose a similar proportionality restriction for the standard set of controls, where $c$ is the set of year, month, and size indicators.

\footnotetext{
${ }^{11}$ Unfortunately, for the delayed response $R_{t, k}^{(2,75)}$ a proportionality restriction like the one that we apply for $R_{t, k}^{(0,1)}$ is not consistent with Figure $1 \mathrm{~b}$.
} 
Column 1 in Table 3 presents the results of specification (12) without control variables on the full sample of 121,381 observations. The $R^{2}$ of .0514 is substantially higher than the $R^{2}$ of 0.0085 for a linear specification $R_{t, k}^{(0,1)}=\alpha+\alpha_{1} s_{t, k}+\phi^{F} s_{t, k} d_{t, k}^{F}+\gamma d_{t, k}^{F}+\varepsilon_{t, k}$. The coefficients $\alpha_{j}$ are precisely estimated and are monotonic in the surprise quantile $j$, mirroring the patterns in Figure 1a. For example, relative to quantile 6, quantile 1 is associated with -3.06 percent returns $\left(\alpha_{1}=-.0306\right)$, and quantile 11 with 3.54 percent returns $\left(\alpha_{11}=.0354\right)$. Turning to the main prediction of the model, the relationship between earnings surprises and immediate stock returns is 18.74 percent flatter for Friday announcements $\left(\hat{\phi}^{F}=-.1874\right)$. The effect is precisely estimated and consistent with the finding of an 18.6 percent lower immediate response for the extreme quantiles (Table 2A). In Column 2 we introduce the controls for year, month, and size. The effect of the controls (not shown in Table 3A) is to increase the stock response to earnings announcements for the more recent years, for mid-size firms, and for December announcements. With these controls, the immediate stock reaction is 16.33 percent flatter for Friday announcements $\left(\hat{\phi}^{F}=-.1633\right)$, a significant difference.

In Column 3 we allow for a different response on each weekday:

$$
R_{t, k}^{(0,1)}=\left(\alpha_{6}+\sum_{j \neq 6} \alpha_{j} d_{t, k}^{j}\right) *\left(1+\sum_{w} \phi^{w} d_{t, k}^{w}\right) * \prod_{c}\left(1+\Gamma_{c} X_{t, k}^{c}\right)+\varepsilon_{t, k},
$$

where $d_{t, k}^{w}$ are indicator variables for announcement of company $k$ in quarter $t$ in weekday $w$ (Wednesday is the omitted category). The immediate stock response is significantly different (lower) only for Friday announcements.

We consider an alternative functional form employing the inverse tangent (arctan) function (Kothari, 2001) instead of a step function as in (12) and (13):

$$
R_{t, k}^{(0,1)}=\left(\phi_{0}+\phi_{2} \arctan \left[\phi_{1} s_{t, k}\right] *\left(1+\phi_{p o s} d_{p o s}\right)\right) *\left(1+\phi^{F} d_{t, k}^{F}\right) * \prod_{c}\left(1+\Gamma_{c} X_{t, k}^{c}\right)+\varepsilon_{t, k} .
$$

This function produces the S-shaped pattern evident in Figure $2 \mathrm{~b}$ with only three parameters $\left(\phi_{0}, \phi_{1}\right.$, and $\left.\phi_{2}\right)$. In addition, the parameter $\phi_{\text {pos }}$ permits a different sensitivity to positive surprises $\left(d_{\text {pos }}\right)$ relative to negative surprises. In this specification (Column 4 ), the $R^{2}$ is slightly higher than the $R^{2}$ for the baseline specification (Column 2), even though the arctan function has 5 , rather than 12 parameters. The immediate stock returns are 22.24 percent more responsive to positive surprises than to negative surprises $\left(\hat{\phi}_{\text {pos }}=.2224\right)$. Most importantly, this responsiveness is 15.52 percent flatter for Friday announcements $\left(\hat{\phi}^{F}=-.1552\right)$. The result is precisely estimated and the point estimate is very similar to the estimate obtained using the baseline specification (16.33 percent).

In the Homogeneous Sample (Column 5), stock returns in the short-run respond 12.52 percent less to Friday earning surprises than to non-Friday earning surprises. Given the smaller sample, the result is less precisely estimated and only marginally significant, but the point estimate is comparable to the one based on the whole sample (16.33 percent). 
To remove the effect of potential earnings surprise outliers, we replicate the specifications in Columns 2 and 5 for the 121,381 announcements with $a b s\left(s_{t, k}\right)<.02$, that is, with surprises that do not exceed two percent of market capitalization. ${ }^{12}$ For this sample, the Friday coefficient $\phi^{F}$ is actually more negative: the stock response to earnings announcements is 20.94 percent flatter than on other weekdays (Column 6). In the Homogeneous Sample with $a b s\left(s_{t, k}\right)<.02$ (Column 7 ), the Friday effect is a significant 17.74 percent.

So far, we have shown that the same-day and next-day stock reaction is flattened for Friday announcements. Ideally, we would like to test whether the flattening occurs on Friday, before the weekend, or on Monday, after the weekend. However, this comparison requires that the fraction of announcements taking place after market close be similar for Friday and non-Friday announcements. Unfortunately, Friday announcements during the recent years are significantly less likely to occur after hours (Bagnoli et al., 2004), making a direct comparison impossible.

Summary. Friday announcements are associated with a 12 to 21 percent lower response of stock prices in the two days surrounding the announcement. These results are not sensitive to the introduction of controls or specification modifications, and are consistent with the results obtained using only the top and bottom quantile (Table 2A). The decreased initial response fits the hypothesis that Friday and the weekend temporarily distract investors.

\section{Volume response}

In the previous Section, we documented that the immediate stock response to Friday earnings announcements is substantially lower than for non-Friday announcements. If this difference is caused by investor distraction associated with the weekend, we expect that fewer investors should place trades in response to Friday news. In this Section, we test if, indeed, the abnormal volume around the announcement day is lower for Friday than for non-Friday announcements. ${ }^{13}$

The measure for abnormal volume is

$$
\Delta v_{t, k}^{(h, H)}=\sum_{u=h}^{H} \log \left(V_{t, k}^{u}\right) /(H-h+1)-\sum_{u=-20}^{-11} \log \left(V_{t, k}^{u}\right) / 10,
$$

where $V_{t, k}^{\tau}$ is the value of the shares traded on the $\tau$-th trading day after the earning announcement in quarter $t$ of company $k$. The measure $\Delta v_{t, k}^{(h, H)}$ is the percentage increase in volume around announcement date at horizon $(h, H)$, relative to baseline volume for stock $k$ in quarter $\tau$. In particular, $\Delta v_{t, k}^{(0,1)}$ is the immediate abnormal volume due to the announcement.

Graphical evidence. Figure 3 plots the average abnormal volume $\Delta v_{t, k}^{(h, H)}$ at various horizons. We consider first the non-Friday announcements. Abnormal trading volume is essentially zero two days before the announcement and is about 5 percent the day before. The

\footnotetext{
${ }^{12}$ The results are similar for other thresholds, such as trimming 2 or 5 percent of the most extreme surprises.

${ }^{13}$ This prediction does not follow from the model because it has no natural definition of trading volume.
} 
abnormal volume increases to 45 percent on the day of the announcement, to 58 percent on the next trading day, and then it decays slowly. A week after the announcement, the trading volume is still 12 percent higher than in the baseline period.

Next, we consider the Friday announcements. The measures of abnormal volume are very similar to the non-Friday announcements for the days preceding the announcement. On announcement day, abnormal volume is 10 percent higher for Friday announcements. Most importantly, abnormal volume is 40 percent lower on the day after the announcement. On trading days $\tau+2$ and $\tau+3$, the Friday and non-Friday series are again very similar. On trading days $\tau+4$ and $\tau+5$ abnormal volume is somewhat lower on Friday.

The main difference between Friday and non-Friday announcements occurs during the day of and the day after the announcement. Abnormal volume $\Delta v_{t, k}^{(0,1)}$ is substantially lower for Friday than for non-Friday announcements. (The measures $\Delta v_{t, k}^{(0,0)}$ and $\Delta v_{t, k}^{(1,1)}$ need to be considered together because the share of after-hour announcements is lower on Friday, as discussed in Section 4.4) Our interpretation of this finding is that the weekend distracts investors. Consequently, trade does not increase as much in response to new information released on Friday. This interpretation also suggests why the difference between Friday and non-Friday announcements mostly disappears by day $\tau+2$. Two offsetting forces are at work. On the one hand, some of the investors that have been distracted by the weekend are still not trading. On the other hand, other investors trade to respond to the underreaction after the weekend.

Regressions. We test whether the finding of lower abnormal volume $\Delta v_{t, k}^{(0,1)}$ for Friday announcements is affected by adding control variables. We run the OLS specification

$$
\Delta v_{t, k}^{(0,1)}=\alpha+\sum_{j \neq 6} \alpha_{j} d_{t, k}^{j}+\phi^{F} d_{t, k}^{F}+\Gamma X_{t, k}+\varepsilon_{t, k}
$$

The terms $d_{t, k}^{j}$ are indicators for earning surprises $s_{t, k}$ in the $j$-th quantile, with quantile 6 $\left(s_{k, t}=0\right)$ as the omitted category. The control variables $X_{t, k}$, as usual, are month, year, and size indicators. In the specification without controls (Column 1 of Table 4) the abnormal volume is increasing in the absolute value of the earnings surprise. It is lowest for the case of no-surprise (43.93 percent) and it equals 57.75 percent for the most negative and 66.41 percent for the most positive surprise. Most importantly, the Friday coefficient is negative and significant, $\hat{\phi}^{F}=-.1052$. Compared to the average immediate volume increase on non-Fridays, .5161 , the abnormal volume increase on Friday is $.1052 / .5161=20.3$ percent lower.

In Column 2 we introduce the controls. The abnormal volume is lowest in years 1999-2002, for larger firms and during the peak of the earnings season (April, July, and October). With controls, the Friday effect is larger $\left(\hat{\phi}^{F}=-.1243\right)$. In Column 3 we introduce firm fixed effects to control for company-level differences in abnormal volume that are not captured by the controls. This specification reduces the differential volume increase for Friday announcements to a still highly significant $\hat{\phi}^{F}=-0.0480$. The decrease in the coefficient indicates that some 
of the Friday effect was due to heterogeneity in abnormal volume among firms. However, the remaining Friday effect is large and precisely estimated. When companies announce on Friday, they have $.0480 / .5161=9.3$ percent lower abnormal volume compared to when they announce on another weekday. The 9.3 percent attenuation of abnormal volume is similar to the 12 to 20 percent flattening of short-run stock returns (Tables 2A and 3). Since controlling for firm fixed effects appears to be important, we include them in all the subsequent specifications. In Column 4, we estimate separate effects for each weekday. Compared to Wednesday announcements, Friday announcements have the lowest volume, followed by Thursday announcements. In the Homogeneous Sample (Column 5), the abnormal volume is 0.0669/.5161 = 12.9 percent lower for Friday announcements, a result larger than in the whole sample.

Abnormal volume is lower for Friday announcements, even after controlling for firm heterogeneity. This does not necessarily imply investor inattention. The lower abnormal volume for Friday announcements may be explained by the well-known fact that aggregate market volume is lower on Monday. Of course, our hypothesis predicts that aggregate volume should be lower on Friday and Monday if investors are more distracted. Nevertheless, at the risk of removing the aggregate impact of inattention, we include aggregate volume as an additional control. We measure aggregate volume as the equal-weighted average across firms of the number of shares traded, divided by shares outstanding. We then generate the abnormal aggregate volume $\Delta v_{t, A}^{(0,1)}$ using the same formula as in (15). After controlling for abnormal aggregate volume (Column 6), Friday announcements have a 2.14 percent lower abnormal volume, but the result is no longer significant. In Column 7, we replicate this specification for the Homogeneous Sample of Column 5. In this sample, abnormal volume for Friday announcements is significantly lower than on other weekdays by $.0432 / .5161=8.3$ percent, even after controlling for aggregate volume. Controlling for aggregate volume, therefore, lowers the effect, but the Friday result is still significant in the Homogenous Sample.

Summary. Short-term abnormal volume is significantly lower for Friday earnings announcements, even after controlling for announcement quality, control variables, and firmspecific variation. The result holds even after controlling for aggregate market volume in one of two samples. The Friday effect in abnormal volume is of the same order of magnitude as the Friday effect in immediate returns. The volume results are consistent with the hypothesis that investors underreact initially to information released on Friday.

\section{Firm reaction}

We interpret the evidence in the previous two Sections as suggesting that investors pay less immediate attention to announcements occurring on Friday. If inattention is indeed higher on Friday, the model in Section 2 predicts that earnings quality and returns should be lower for Friday announcements, as long as some managers maximize short-term value. For example, 
managers may be interested in short-term value if they intend to exercise stock options in the near future and they expect to release negative news. Given that they cannot exercise the options before the earnings announcement due to insider trading regulation, a delayed response to the news allows the managers to exercise the options at a higher price.

Graphical evidence. The first measure of earnings quality is whether the company announces negative operating profits for the quarter. Companies manipulate earnings to avoid announcing negative earnings (Degeorge, Patel, and Zeckhauser, 1999). The frequency of negative earnings announcements by day of week (Figure 4a) varies between .187 and .200 between Monday and Thursday. On Friday, the fraction of negative announcements is .240, 25 percent higher than on other weekdays.

The second measure of earnings quality is whether the earnings announcement falls short of the consensus analyst forecast. On Monday through Thursday, the fraction of negative surprises varies between .266 and .288 (Figure 4b). On Friday, instead, the fraction of negative surprises is .400. Friday announcements, therefore, are 45 percent more likely to fail to meet analyst expectations. Analyst forecasts do not fully reflect the extent of bad news on Friday.

While Figure $4 \mathrm{~b}$ focuses on the fraction of announcements falling short of analyst expectations, Figure 5 presents the full distribution by earning surprise quantile. We find three main effects. First, Friday surprises are almost twice as likely to be very negative (quantile 1) and are substantially more likely to be in quantiles 2,3 , and 4 . Second, Friday announcements are twenty percent less likely to have a zero surprise (quantile 6). Third, Friday announcements are less likely to be barely positive, but no less likely to be substantially positive (quantiles 10 and 11). An interpretation of these patterns is that some companies announce on Friday if they have substantially negative earnings. In addition, if firms announce on Friday, they are less likely to manipulate earnings in order to generate barely positive surprises.

The third measure of earnings quality is the abnormal stock return on the day of, and the day after, the announcement, $R_{t, k}^{(0,1)}$. On Monday through Thursday the return varies between -.0012 and .0021, while on Friday it equals -.0038 (Figure 4c). Average returns on Friday are 50 basis points lower than on other days. These results confirm the earlier findings of Damodaran (1989) for the period 1981 through 1985. Investors (as well as analysts) are surprised by the extent of negative news released on Friday.

Regressions. While this evidence is suggestive of timing of negative news on Friday, alternative interpretations are possible. Firms announcing on Friday may have unobservable features that are associated with negative earnings surprises and abnormal returns. This would also explain the findings in Damodaran (1989) and Bagnoli et al. (2004). To address this explanation, we estimate specifications with controls and firm fixed effects. We adopt the logit specification:

$$
q_{t, k}=1 \text { if } q_{t, k}^{*}=\phi_{0}+\phi^{F} d_{t, k}^{F}+\Gamma X_{t, k}+\varepsilon_{t, k} \geq 0
$$

where $q_{t, k}$ is the (binary) measure of announcement quality by company $k$ in quarter $t, d_{t, k}^{F}$ 
is an indicator for Friday announcement, $X_{t, k}$ is the vector of controls, and $\varepsilon_{t, k}$ has a logistic distribution. We also estimate a conditional logit specification, which includes firm fixed effects. In both cases, we present the results as odds ratios, where the odds are defined as the ratio of the probability of a high-quality versus low-quality announcement, $P\left(q_{t, k}\right) /\left(1-P\left(q_{t, k}\right)\right)$.

The first measure of earnings quality $q_{t, k}$ is an indicator variable for negative announcements (Table 5A). Without controls (Column 1), the odds ratio for $\hat{\phi}^{F}$ is 1.327 , significantly larger than 1, indicating that Friday announcements are more likely to deliver negative earnings. This corresponds to the finding in Figure 4a that Friday announcements are 25 percent more likely to be negative. The odds ratio for $\hat{\phi}^{F}$ is still significantly larger than 1 after introduction of controls (Column 2). In Column 3 we present the results of a conditional logit model, which includes firm fixed effects. ${ }^{14}$ In this specification, the dependent variable is identified only by within-company differences in earnings quality between Friday and non-Friday announcements. Unlike in the results in Columns 1 and 2, heterogeneity across companies does not contribute to the identification. In this specification, the number of observations is lower, since any company $k$ for which the dependent variable $e_{t, k}$ does not vary with time is automatically dropped from the sample. With company fixed effects, the odds ratio for $\hat{\phi}^{F}$ equals 1.759, which is substantially larger than the benchmark odds ratio of 1.327. Of the other weekdays, only Thursday has significantly worse earnings than on Wednesday, although the effect is only one tenth of the Friday effect (Column 4). Finally, in the Homogeneous Sample (Column 5), the odds ratio is 1.617 , still a very large effect.

The second measure of earnings quality $q_{t, k}$ is an indicator variable for announcements with negative surprises (Table 5B). Without control variables (Column 1), the odds ratio for $\hat{\phi}^{F}$ is 1.755 , corresponding to the finding in Figure $4 \mathrm{~b}$ that Friday announcements are 45 percent more likely to disappoint analysts. The introduction of control variables (Column 2) and firm fixed effects (Column 3) reduces the estimated difference. Even in the specification with firm fixed effects, though, the odds ratio for $\hat{\phi}^{F}$ is 1.365, a large and precisely estimated effect. Friday earnings surprises are significantly more likely to be negative than surprises announced on any other weekday (Column 4). The results in the Homogeneous Sample (Column 5) are similar to the baseline results in Column 3.

The third measure of earnings quality is the short-run abnormal stock return $R_{t, k}^{(0,1)}$ (Table 5C). We estimate the OLS specification:

$$
R_{t, k}^{(0,1)}=\phi_{0}+\phi^{F} d_{t, k}^{F}+\Gamma X_{t, k}+\varepsilon_{t, k} .
$$

The average return is 13 basis points for non-Friday announcements $\left(\hat{\phi}_{0}=.0013\right)$ and -38 basis points for Friday announcements $\left(\hat{\phi}_{0}+\hat{\phi}^{F}=-.0038\right.$, Column 1). The 51 basis point difference is large and significant. This difference remains essentially unchanged after the introduction

\footnotetext{
${ }^{14}$ For the conditional logit specifications in Columns 3 and 4 we present unclustered robust standard errors. Clustering by day is not possible with this specification.
} 
of controls (Column 2) and of company fixed effects (Column 3). Compared to Wednesday announcements, Friday announcements, and (to a lesser extent) Monday announcements, have lower average returns (Column 4). Finally, the difference of returns is similar in the Homogeneous Sample (Column 5).

Summary. Companies release more negative announcements on Friday, even after controlling for firm-specific announcement behavior. Analysts as well as investors appear to be surprised by the lower quality of the earnings surprise announced on Friday. The managerbased evidence of strategic news release supports the investor-based finding of inattention on Friday. Managers act as if distracted investors affect stock prices.

\section{$7 \quad$ Alternative interpretations}

In this Section we consider two standard explanations of the findings, pre-announcement release and firm heterogeneity. We also discuss an attention-related interpretation that is inconsistent with the data.

Pre-announcement release. Companies release in advance the date of the earnings announcements. In the event of poor performance, companies may also issue earnings warnings. These pre-announcement releases could explain the lower immediate reaction of stock prices to Friday announcements. Assume that firms announcing on Friday are more likely to issue earnings warnings. Additionally, the decision to announce on Friday, itself, could be interpreted as a warning about earnings. Stock prices may respond to this news before the official earnings announcement. Because the consensus forecast is not always revised after these pre-announcements, the negative surprises constructed from the consensus forecast may overestimate the actual magnitude of the surprise to investors. This hypothesis can explain a lower short-term reaction of stock returns to negative surprises. However, it does not explain the attenuated short-term reaction for positive surprises. If anything, it predicts a stronger short-term response to positive announcements. This interpretation is also unable to explain differential drift. Further, we can directly test whether investors perceive more negative news before Friday releases. Figure 1d display stock returns for the horizon $(-30,-1)$ as a function of the quantiles of earnings surprises. The pre-announcement returns are very similar for Friday and non-Friday announcements.

Firm heterogeneity. The attenuated immediate response on Friday could be due to unobserved heterogeneity. For example, the news about future profitability embedded in earnings announcements may be more transitory for firms making Friday announcements. While it is impossible to fully control for firm heterogeneity, we show that the results remain qualitatively unchanged after the introduction of time, company, and market capitalization controls. In addition, heterogeneity is unlikely to simultaneously produce less immediate response and more delayed response for Friday announcements. Finally, if firm heterogeneity is also responsible 
for the results, it should also explain why earnings surprises and returns are worse for Friday announcements even after introducing firm fixed effects.

Task overload. An attention-related interpretation is that investors on Monday are overburdened by the information that has accumulated on their desks during the weekend and they find less time to react to Friday earnings announcements. Two pieces of evidence are not consistent with this interpretation. First, the stock return and volume response to Monday announcements does not appear to be attenuated (Column 4 in Tables 3 and 4). Second, if traders are overburdened by information on Monday we should expect aggregate high trading volume on Monday. Instead, aggregate volume is 10 percent lower on Monday.

\section{Conclusion}

We have compared the reaction to earnings announcements on Friday to the reaction on other weekdays. Friday announcements are characterized by a lower immediate, and a higher delayed, response. The delayed response as a percentage of the total response is 60 percent on Friday and 40 percent on other weekdays. We observe parallel results for volume. Abnormal volume increase around the day of announcement is 10 percent smaller for Friday announcements than for non-Friday announcements.

The evidence supports the inattention hypothesis. On Friday, investors are distracted from work-related activities. Given limited attention, distractions cause underreaction to the earnings information. Eventually, investors realize the mispricing and incorporate the information.

Firms respond to investor inattention by releasing worse announcements on Friday. This strategic behavior takes analysts as well as investors by surprise. Friday announcements are 45 percent more likely to miss analyst expectations. These announcements are also associated with an abnormal stock return that is 50 basis points lower.

Our results contribute to the debate on the causes of momentum and post-announcement drift. The evidence that a distracting event increases the delayed reaction supports the theory that underreaction to new information is a source of the drift.

The strategic release of worse news on Friday appears to occur in other domains beyond corporate decisions. In ongoing work, we show that on Friday or on a weekend the Unites States President is 10 percent less likely to sign legislation that is likely to be politically popular. Interestingly, our findings for financial markets suggest that releasing negative information on Friday has only a temporary effect. Whether or not the strategic release of political news has permanent effects is an open question. 


\section{A Appendix}

Time-invariant perceived variances. We show that $\sigma_{\mu, t, P+D}^{2}$ and $\sigma_{1-\mu, t, P+D}^{2}$ do not depend on $t$. First, we solve for $\sigma_{\mu, t, P+D}^{2}$ :

$$
\begin{aligned}
\sigma_{\mu, t, P+D}^{2} & =E_{t}^{\mu}\left[\left(P_{t+1}+D_{t+1}-E_{t}^{\mu}\left[P_{t+1}+D_{t+1}\right]\right)^{2}\right] \\
& =E_{t}^{\mu}\left[\left(\frac{b_{t+1} s_{t+1}-a_{t+1}-\left(E_{t}^{\mu}\left[b_{t+1} s_{t+1}\right]-\bar{a}\right)}{1+R}+s_{t}+\varepsilon_{t+1}\right)^{2}\right] \\
& =\left(\frac{1}{1+R}\right)^{2} \sigma_{(1-b) s-a}^{2}+\sigma_{s}^{2}+\sigma_{\varepsilon}^{2}
\end{aligned}
$$

since $s_{t}$ and $\varepsilon_{t+1}$ are independent of each other and of all the other variables. Similarly, one can show that $\sigma_{1-\mu, t, P+D}^{2}=\left(\frac{1}{1+R}\right)^{2} \sigma_{(1-b) s-a}^{2}+\sigma_{\varepsilon}^{2}$. Neither expression depends on $t$, if the strategic behavior of managers is time-invariant (as shown in proposition 4).

Comparative statics for $a_{t}$ and $b_{t}$. We substitute the expressions for $\sigma_{\mu, P+D}^{2}$ and $\sigma_{1-\mu, P+D}^{2}$ into the definition of $a_{t}$ to obtain

$$
a_{t}=\gamma\left(\frac{\mu_{t}}{\left(\frac{1}{1+R}\right)^{2} \sigma_{b s-a}^{2}+\sigma_{s}^{2}+\sigma_{\varepsilon}^{2}}+\frac{1-\mu_{t}}{\left(\frac{1}{1+R}\right)^{2} \sigma_{b s-a}^{2}+\sigma_{\varepsilon}^{2}}\right)^{-1} .
$$

Let $k=(1+R)^{-2} \sigma_{(1-b) s-a}^{2}+\sigma_{\varepsilon}^{2}$. By definition, $k>0$. Substituting this definition into the expression for $a_{t}$ and rearranging yields

$$
a_{t}=\gamma\left(\frac{k^{2}+k \sigma_{s}^{2}}{k+\sigma_{s}^{2}\left(1-\mu_{t}\right)}\right)
$$

From this expression it follows that $a_{h}>a_{l}$. Using a similar procedure, one can show that

$$
b_{t}=\frac{k \mu_{t}}{k+\sigma_{s}^{2}\left(1-\mu_{t}\right)}
$$

which implies that $b_{h}>b_{l}$.

Proof of Proposition 1. (i) By the definition of $I R_{t}$,

$$
\begin{aligned}
E_{t}\left[I R_{t}\right] & =E_{t}\left[Z_{t}-E_{t-1}\left[Z_{t}\right]-\left(D_{t}-E_{t-1}\left[D_{t}\right]\right)\right]=P_{t}-E_{t-1}\left[P_{t}\right]= \\
& =-\frac{a_{t}-\bar{a}}{1+R}+\frac{\left(1-b_{t}\right) s_{t}-E_{t-1}\left[\left(1-b_{t}\right) s_{t}\right]}{1+R}=\frac{\bar{a}-a_{t}}{1+R}+\frac{\sigma_{b s}}{1+R}+\frac{1-b_{t}}{1+R} s_{t} .
\end{aligned}
$$

The proof of (ii) follows from $b_{h}>b_{l}$. Q.E.D. 
Proof of Proposition 2. (i) We calculate $E_{t}\left[Z_{t+1}\right]$.

$$
\begin{aligned}
E_{t}\left[Z_{t+1}\right] & =E_{t}\left[P_{t+1}+D_{t+1}-(1+R) P_{t}\right] \\
& =\frac{\delta-\bar{a}}{R}-\frac{E_{t}\left[b_{t+1} s_{t+1}\right]}{1+R}+\delta+s_{t}-\frac{\delta-\bar{a}}{R}-\delta+a_{t}-\left(1-b_{t}\right) s_{t} \\
& =a_{t}-\frac{\sigma_{b s}}{1+R}+b_{t} s_{t} .
\end{aligned}
$$

This implies $E_{t}\left[D R_{t}\right]=E_{t}\left[Z_{t+1}\right]-E_{t-1}\left[Z_{t+1}\right]=a_{t}-\bar{a}+b_{t} s_{t}-E_{t-1}\left[b_{t} s_{t}\right]=a_{t}-\bar{a}-\sigma_{b s}+b_{t} s_{t}$. The proof of (ii) follows from $b_{h}>b_{l}$. Q.E.D.

Proof of Proposition 3. (i) Notice that $Z_{t+1, t-1}$ can be rewritten as $Z_{t+1}+(1+R) Z_{t}$. We can substitute this expression for $Z_{t+1, t-1}$ into the expression for $E_{t}\left[L R_{t+1}\right]$ (in the text) to obtain

$$
\begin{aligned}
E_{t}\left[L R_{t+1}\right] & =\left[\left(E_{t}\left[Z_{t}\right]-E_{t-1}\left[Z_{t-1}\right]\right)-\left(E_{t}\left[D_{t}\right]-E_{t-1}\left[D_{t}\right]\right)\right]+\frac{E_{t}\left[Z_{t+1}\right]-E_{t-1}\left[Z_{t+1}\right]}{1+R} \\
& =E_{t}\left[I R_{t}\right]+\frac{E_{t}\left[D R_{t}\right]}{1+R}
\end{aligned}
$$

Parts (ii) and (iii) follow from this expression for $E_{t}\left[L R_{t+1}\right]$ and Propositions 1 and 2. Q.E.D.

Proof of Proposition 4. Parts (i) and (iii) are discussed in the body of the paper. We prove part (ii). The problem (7) of the short-term manager is equivalent to solving $\max _{\mu_{t} \in\left\{\mu_{h}, \mu_{l}\right\}}-a_{t}-b_{t} s_{t}$. Substituting in the values of $a_{t}$ and $b_{t}$, we obtain

$$
\max _{\mu_{t} \in\left\{\mu_{h}, \mu_{l}\right\}}\left(-\gamma-\frac{\mu_{t} s_{t}}{k+\sigma_{s}^{2}}\right)\left(\frac{\mu_{t}}{k+\sigma_{s}^{2}}+\frac{1-\mu_{t}}{k}\right)^{-1}
$$

where $k=(1+R)^{-2} \sigma_{b s-a}^{2}+\sigma_{\varepsilon}^{2}>0$. Announcing on a high-distraction day is optimal if and only if

$$
\begin{aligned}
\left(-\gamma-\frac{\mu_{h} s_{t}}{k+\sigma_{s}^{2}}\right)\left(\frac{\mu_{h}}{k+\sigma_{s}^{2}}+\frac{1-\mu_{h}}{k}\right)^{-1} & \geq\left(-\gamma-\frac{\mu_{l} s_{t}}{k+\sigma_{s}^{2}}\right)\left(\frac{\mu_{l}}{k+\sigma_{s}^{2}}+\frac{1-\mu_{l}}{k}\right)^{-1} \text { or } \\
\left(\gamma\left(k+\sigma_{s}^{2}\right)+\mu_{h} s_{t}\right)\left(\left(k+\sigma_{s}^{2}\right)-\sigma_{s}^{2} \mu_{l}\right) & \leq\left(\gamma\left(k+\sigma_{s}^{2}\right)+\mu_{l} s_{t}\right)\left(\left(k+\sigma_{s}^{2}\right)-\sigma_{s}^{2} \mu_{h}\right) .
\end{aligned}
$$

Multiplying the terms together and simplifying leads to $\mu_{h} s_{t}-\gamma \sigma_{s}^{2} \mu_{l} \leq \mu_{l} s_{t}-\gamma \sigma_{s}^{2} \mu_{h}$, and finally to $s_{t} \leq-\sigma_{s}^{2} \gamma$, the desired condition. Given this threshold rule, $E\left[s_{t} \mid \mu_{t}=\mu_{h}\right]<0$ and $E\left[s_{t} \mid \mu_{t}=\mu_{l}\right]>0$ follow immediately. Hence, $E\left[s_{t} \mid \mu_{t}=\mu_{h}\right]<E\left[s_{t} \mid \mu_{t}=\mu_{l}\right]$. The relationship $E\left[I R_{t} \mid \mu_{t}=\mu_{h}\right]<E\left[I R_{t} \mid \mu_{t}=\mu_{l}\right]$ follows from

$$
E\left[I R_{t} \mid \mu_{t}=\mu_{h}\right]-E\left[I R_{t} \mid \mu_{t}=\mu_{l}\right]=\frac{a_{l}-a_{h}}{1+R}+\frac{1-b_{h}}{1+R} E\left[s_{t} \mid \mu_{t}=\mu_{h}\right]-\frac{1-b_{l}}{1+R} E\left[s_{t} \mid \mu_{t}=\mu_{l}\right]
$$

because $a_{l}-a_{h}<0, E\left[s_{t} \mid \mu_{t}=\mu_{h}\right]<0$, and $E\left[s_{t} \mid \mu_{t}=\mu_{l}\right]>0$. Q.E.D. 


\section{References}

[1] Bagnoli, Mark, Michael B. Clement, and Susan B. Watts. "The Timing of Earnings Announcements Throughout the Day and Throughout the Week", mimeo, 2004.

[2] Baker, Malcolm, Richard Ruback, and Jeffrey Wurgler. "Behavioral Corporate Finance: A Survey." In The Handbook of Corporate Finance: Empirical Corporate Finance, edited by Espen Eckbo. New York: Elsevier/North Holland, forthcoming.

[3] Barber, Brad M. and Terrance Odean. "All that Glitters: The Effect of Attention and News on the Buying Behavior of Individual and Institutional Investors", mimeo, 2002.

[4] Barberis, Nicholas, Andrei Shleifer, and Robert Vishny. "A model of investor sentiment", Journal of Financial Economics, Vol. 49, 307-343, 1998.

[5] Begley, Joy and Paul Fischer. "Is there Information in an Earnings Announcement Delay?", Review of Accounting Studies, Vol. 3, 347-364, 1998.

[6] Bernard, Victor L. and Jacob K. Thomas. "Post-Earnings-Announcement Drift: Delayed Price Response or Risk Premium?", Journal of Accounting Research, Vol. 27, 1-36, 1989.

[7] Bernard, Victor L. and Jacob K. Thomas. "Evidence That Stock Price Do Not Fully Reflect the Implications of Current Earnings For Future Earnings", Journal of Accounting and Economics, Vol. , 305-340, 1990.

[8] Chan, Louis, Narasimham Jegadeesh, and Josef Lakonishok. "Momentum Strategies", Journal of Finance, Vol. 51, 1681-1713, 1996.

[9] Cremers, K.J. Martijn and Vinay B. Nair. "Governance Mechanisms and Equity Prices," mimeo, 2004.

[10] Damodaran, Aswath. "The Weekend Effect in Information: A Study of Earnings and Dividend Announcements", Review of Financial Studies, Vol. 4, 607-623, 1989.

[11] Daniel, Kent, David Hirshleifer, and Avanidhar Subrahmanyam. "Investor Psychology and Security Market Under-and Overreactions", Journal of Finance, Vol. 53, 1839-1885, 1998.

[12] Degeorge, Francois, Jay Patel, and Richard Zeckhauser. "Earnings Management to Exceed Thresholds", Journal of Business, Vol. 72, 1-33, 1999.

[13] DellaVigna, Stefano and Ulrike Malmendier. "Contract Design and Self-Control: Theory and Evidence", Quarterly Journal of Economics,Vol. 119, 353-402, 2004.

[14] DellaVigna, Stefano and Joshua M. Pollet. "Attention, Demographics, and the Stock Market", mimeo, 2005.

[15] DeLong, J. Bradford, Andrei Shleifer, Lawrence H. Summers, Robert J. Waldmann. "Noise Trader Risk in Financial Markets", Journal of Political Economy, Vol. 98, 703-738, 1990.

[16] Dyck, Alexander and Luigi Zingales. "The Media and Asset Prices", mimeo, 2003. 
[17] Frazzini, Andrea. "The Disposition Effect and Under-Reaction to News", mimeo, 2004.

[18] Gabaix, Xavier and David Laibson. "Shrouded Attributes and Information Suppression in Competitive Markets", mimeo, 2004.

[19] Gabaix, Xavier, David Laibson, Guillermo Moloche and Stephen Weinberg. "The Allocation of Attention: Theory and Evidence", mimeo, 2002.

[20] Glaeser, Edward. "The Political Economy of Hatred", Quarterly Journal of Economics, Vol. 120, 45-86, 2005.

[21] Gompers, Paul, Joy Ishii, and Andrew Metrick. "Corporate Governance and Equity Prices", Quarterly Journal of Economics, Vol. 118, 107-155, 2003.

[22] Graham, John R., Campbell R. Harvey, and Shiva Rajgopal. "The Economic Implications of Corporate Financial Reporting", mimeo, 2004.

[23] Grinblatt, Mark and Bing Han. "The Disposition Effect and Momentum", mimeo, 2002.

[24] Hirshleifer, David and Siew Hong Teoh. "Limited Attention, Information Disclosure, and Financial Reporting", Journal of Accounting and Economics, Vol. 36, 337-386, 2003.

[25] Hong, Harrison and Jeremy Stein. "A Unified Theory of Underreaction, Momentum Trading, and Overreaction in Asset Markets", Journal of Finance, Vol. 54, 2143-2184, 1999.

[26] Huberman, Gur, and Tomer Regev. "Contagious Speculation and a Cure for Cancer: A Nonevent that Made Stock Prices Soar", Journal of Finance, Vol. 56, 387-396, 2001.

[27] Jegadeesh, Narasimhan, and Sheridan Titman. "Returns to Buying Winners and Selling Losers: Implications For Stock Market Efficiency", Journal of Finance, Vol. 48, 65-91, 1993.

[28] Keim, Donald and Robert Stambaugh. "A Further Investigation of the Weekend Effect in Stock Returns", Journal of Finance, Vol. 39, 819-835, 1984.

[29] Kothari, S.P. "Capital Markets Research in Accounting", Journal of Accounting and Economics, Vol. 31, 105-231, 2001.

[30] Lakonishok, Josef and Maurice Levi. "Weekend Effects on Stock Return: A Note", Journal of Finance, Vol. 38, 883-889, 1982.

[31] Moskowitz, Tobias J. and Mark Grinblatt. "Do Industries Explain Momentum?", Journal of Finance, Vol. 54, 1249-1290, 1999.

[32] Patell, James M. and Mark A. Wolfson, "Good News, Bad News and the Intraday Timing of Corporate Disclosures", The Accounting Review, pp. 509-527, 1982.

[33] Shleifer, Andrei. Inefficient Markets: An Introduction to Behavioral Finance. Clarendon Lectures in Economics. Oxford and New York: Oxford University Press, 2000. 


\section{Figures 1a-1d. Stock Response to Earnings Surprise at Different Horizons}

Figure 1a: Response To Earnings Surprise From 0 To 1

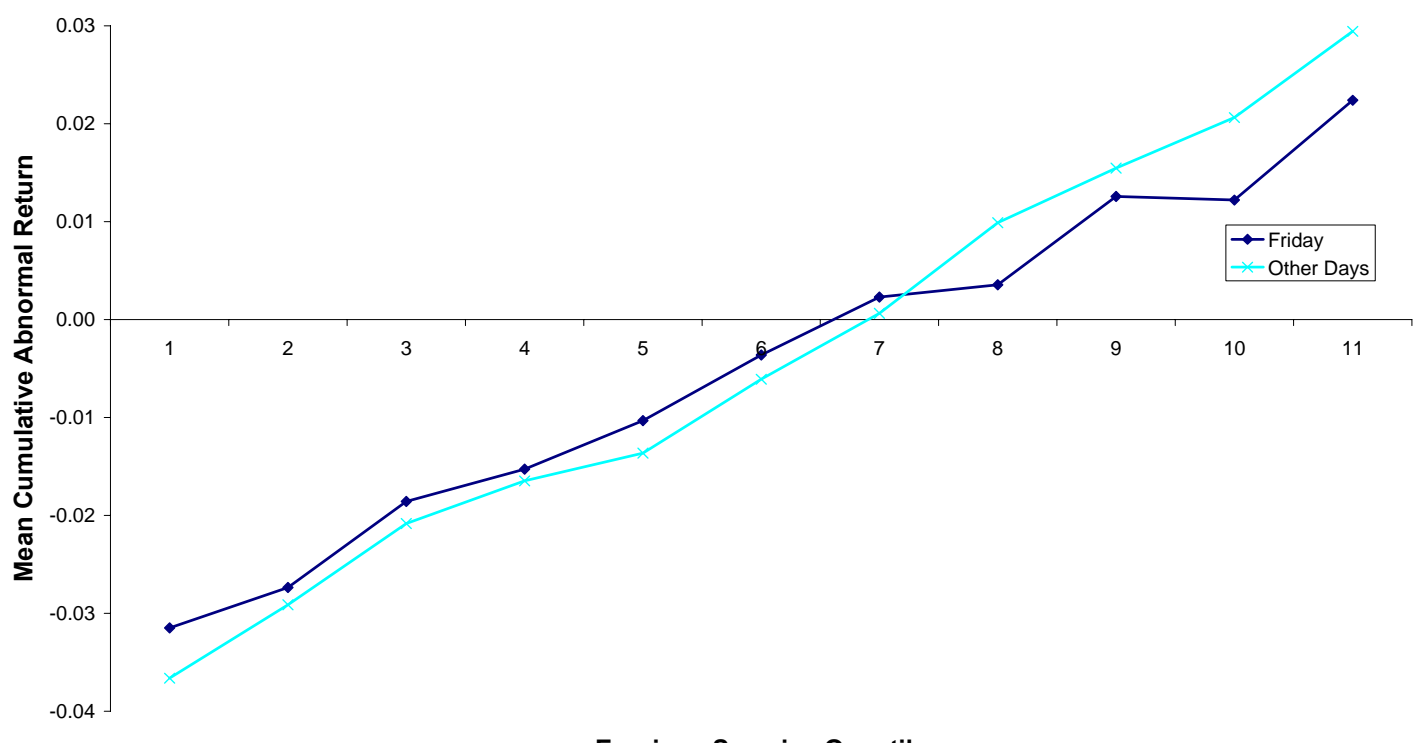

Earnings Surprise Quantile

Figure 1b: Response To Earnings Surprise From 2 To 75

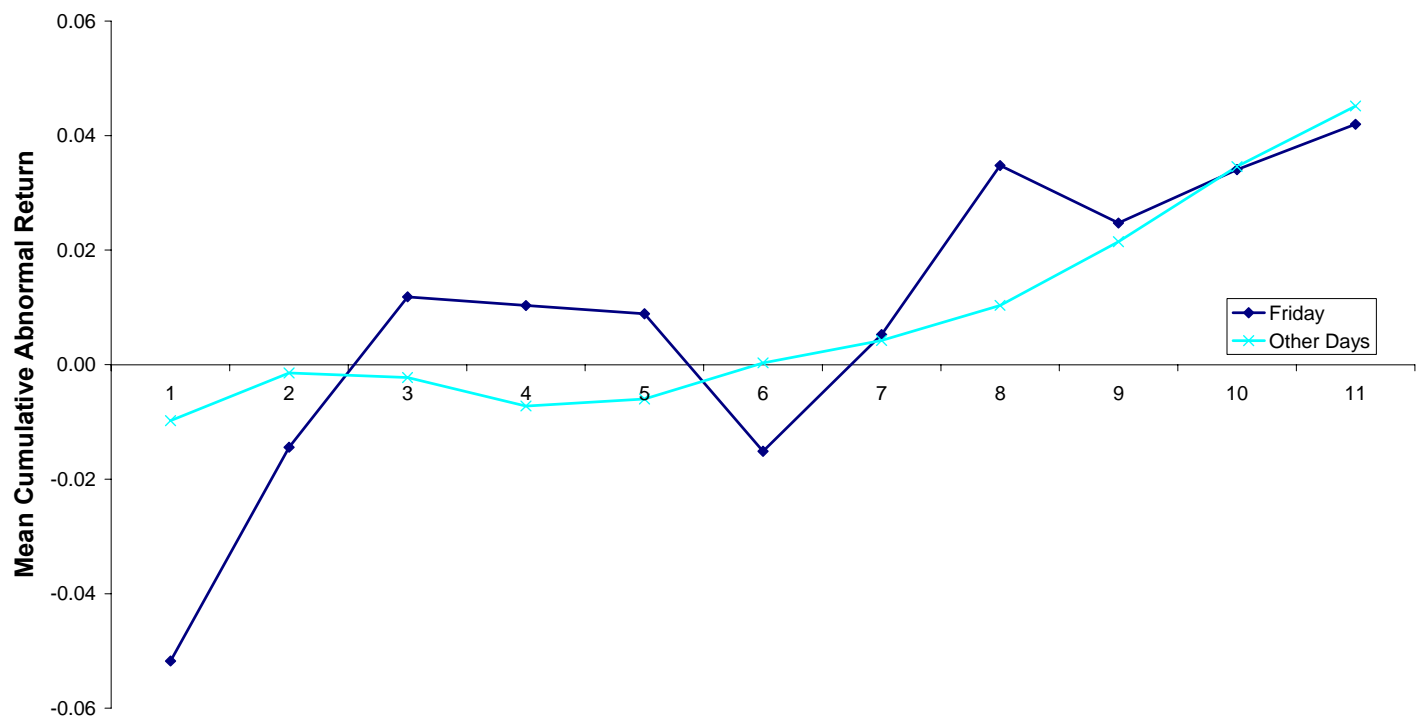

Earnings Surprise Quantile

Notes: The cumulative abnormal return for each stock is the raw buy-and-hold return, adjusted using the estimated beta from market model. Quantiles 1 through 5 contain earnings announcements for five quintiles of negative earnings surprises and quantiles 7 through 11 contain earnings surprises for 5 quintiles of positive earnings surprises. Quantile 6 contains all announcements with an earnings surprise equal to zero. 
Figure 1c: Response To Earnings Surprise From 0 To 75

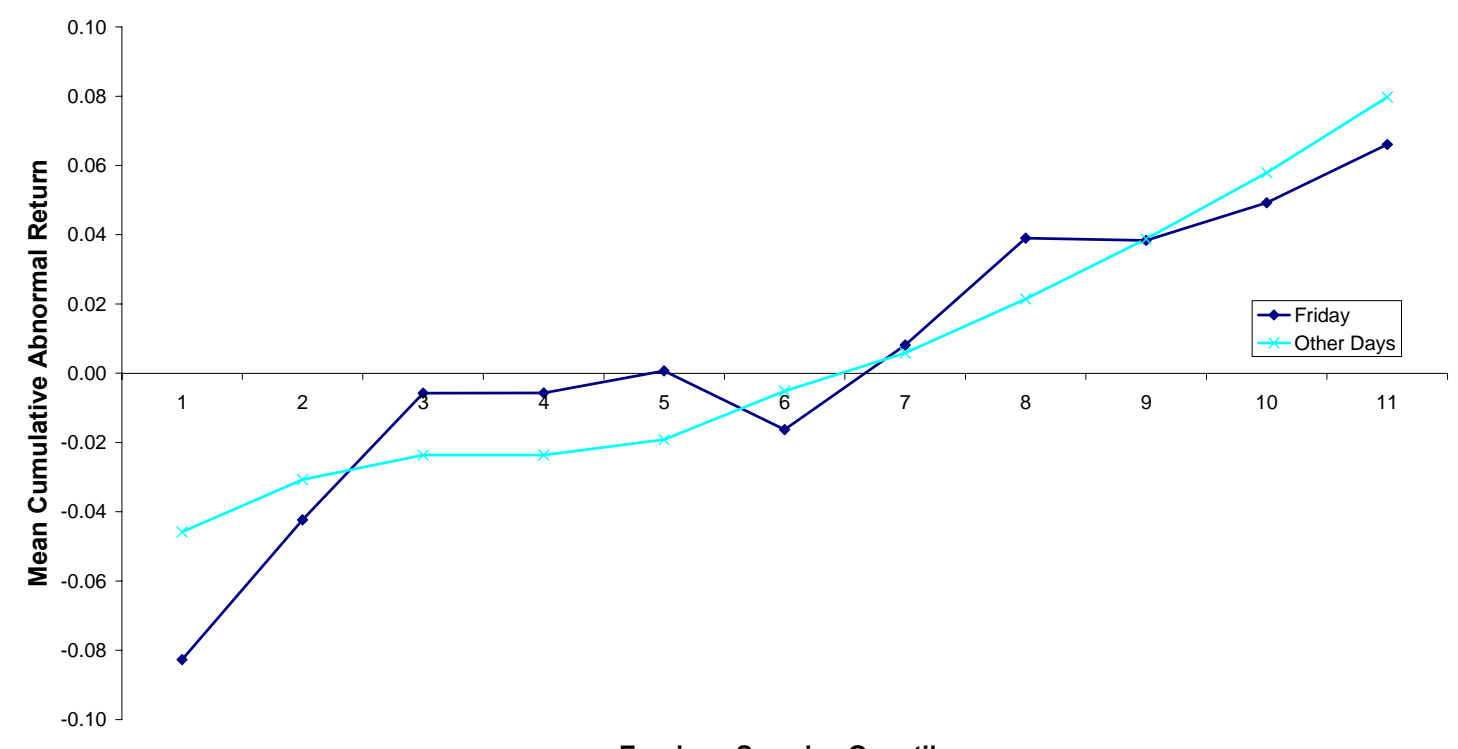

Earnings Surprise Quantile

Figure 1d: Response To Earnings Surprise From -30 To -1

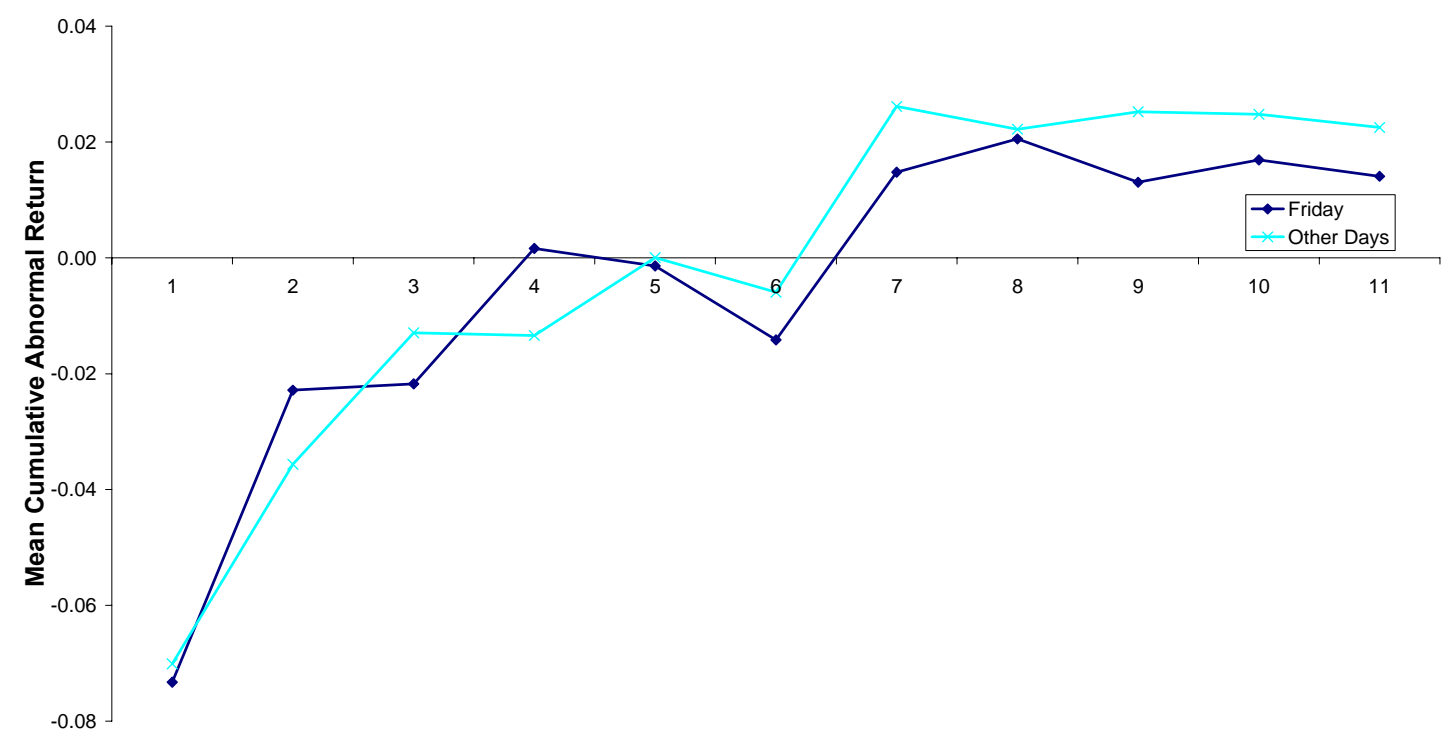

Earnings Surprise Quantile

Notes: The cumulative abnormal return for each stock is the raw buy-and-hold return, adjusted using the estimated beta from market model. Quantiles 1 through 5 contain earnings announcements for five quintiles of negative earnings surprises and quantiles 7 through 11 contain earnings surprises for 5 quintiles of positive earnings surprises. Quantile 6 contains all announcements with an earnings surprise equal to zero. 
Figure 2a: Delayed Response Ratios For Outermost Quantiles

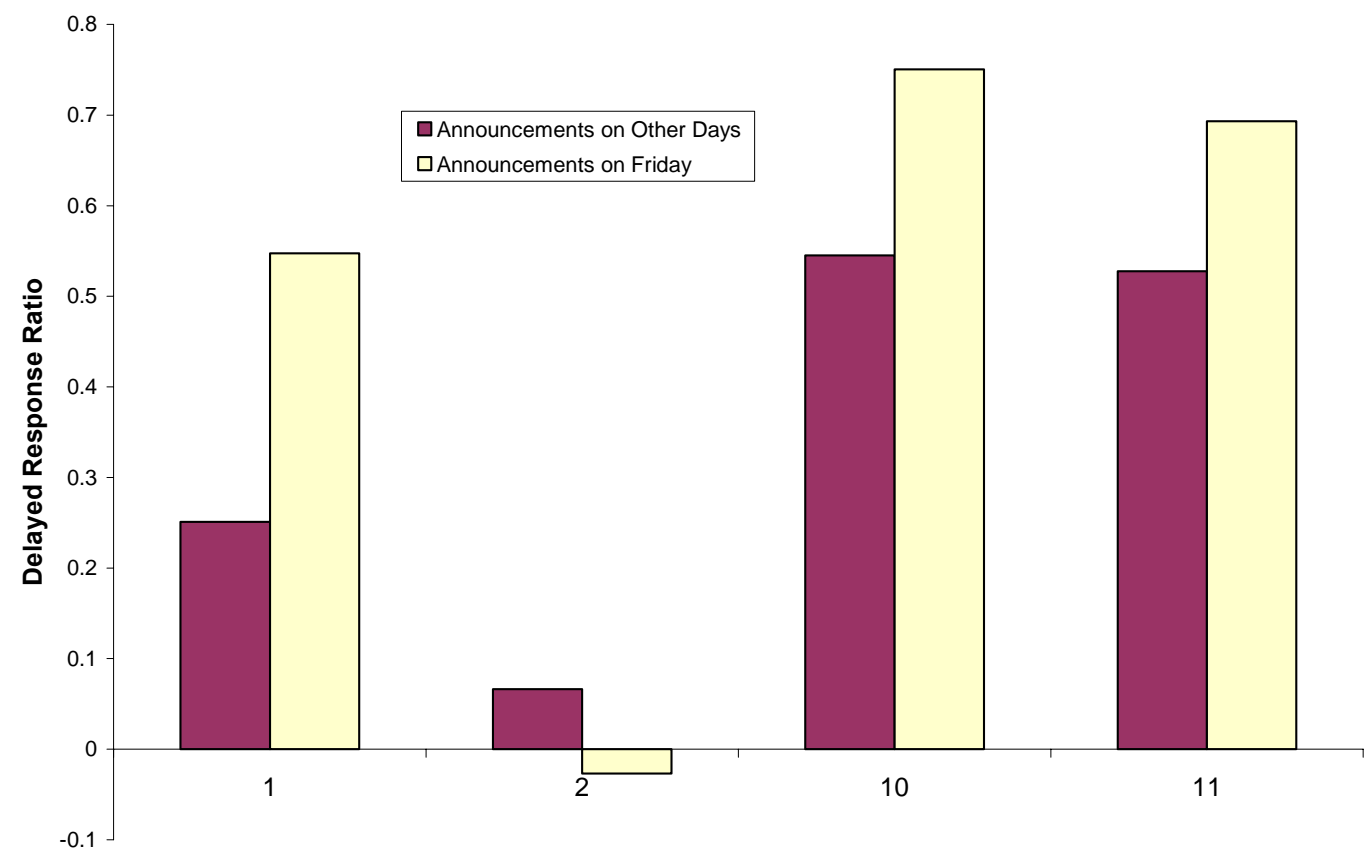

Earnings Surprise Quantile

Figure 2b: Nonlinear Form of the Response to Earnings Surprise From 0 to 1

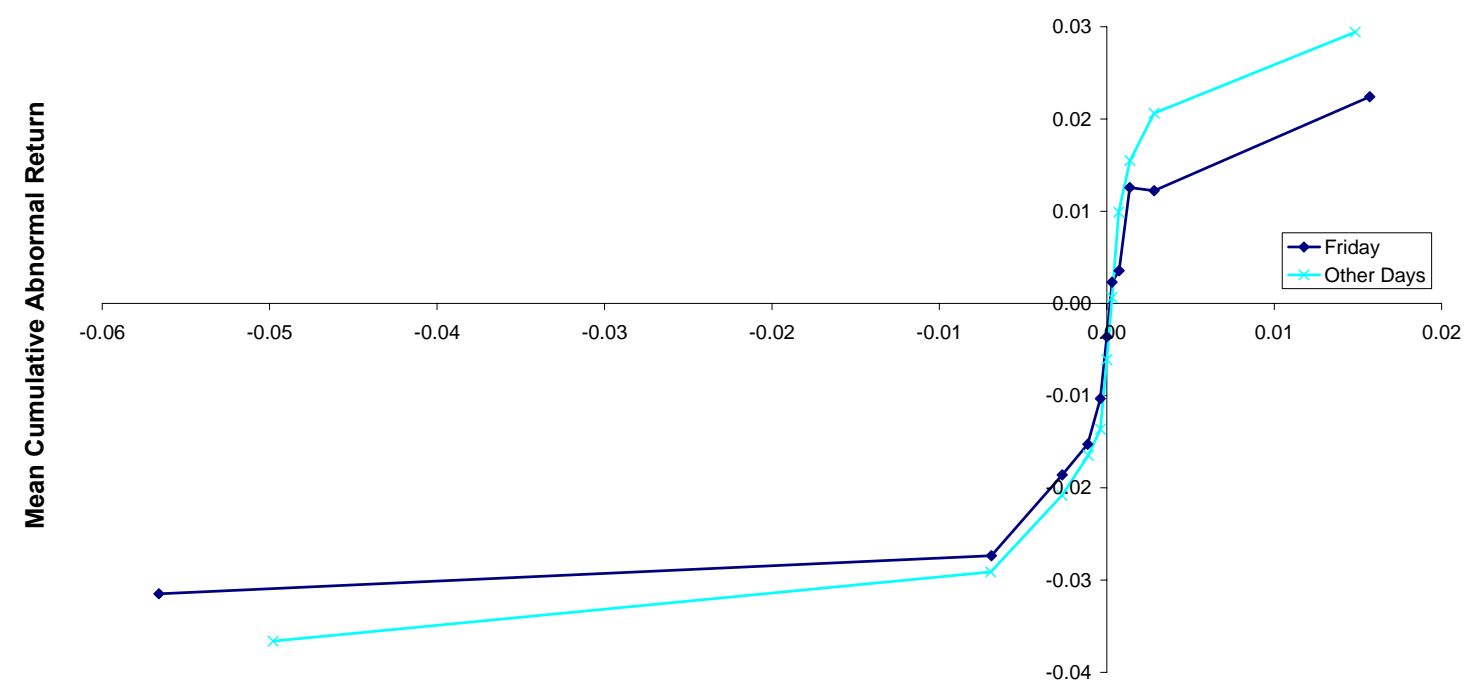

Mean Earnings Surprise For Each Quantile

Notes: The cumulative abnormal return for each stock is the raw buy-and-hold return, adjusted using the estimated beta from market model. Quantiles 1 through 5 contain earnings announcements for five quintiles of negative earnings surprises and quantiles 7 through 11 contain earnings surprises for 5 quintiles of positive earnings surprises. Quantile 6 contains all announcements with an earnings surprise equal to zero. In Figure $2 a$, the Delayed Response Ratio for quantile $\mathrm{j}$ is computed as (Average $(2,75)$ Returns to Quantile $\mathrm{j}$ - Average $(2,75)$ Returns for Quantile 6) / (Average $(0,75)$ Returns to Quantile j - Average $(0,75)$ Returns for Quantile 6). The Delayed Response Ratio on Friday and on other weekdays is significantly different at the $5 \%$ level for Quantiles 10 and 11 . In Figure $2 \mathrm{~b}$, the Quantiles are plotted at the average value of the earnings surprise for that Quantile. 
Figure 3: Abnormal Volume Around Earnings Announcement Date

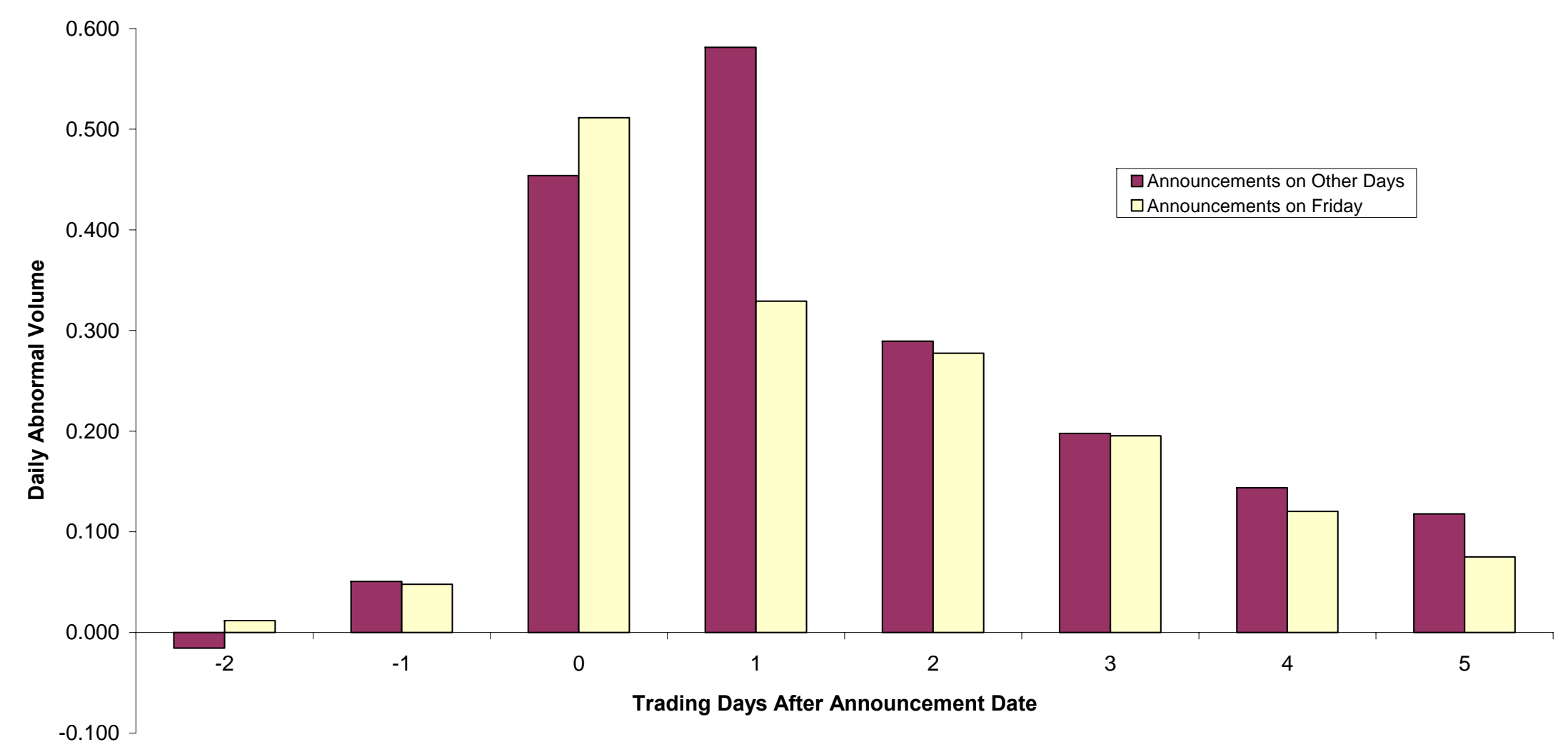

Notes: In event time, day 0 is the day of the earnings announcement. The abnormal volume for each stock for a given event period is the average daily log volume during the period divided by the average log volume for the period -20 to -11 in event time (10 trading days). The earnings surprise for a particular quarterly announcement is the difference between actual earnings per share for the quarter recorded by I/B/E/S and the median analyst forecast included in the I/B/E/S detail file during the 30 days before the quarterly earnings announcement scaled by the stock price 5 trading days before the announcement. 
Figure 4. Firm Timing of Earnings Announcements

Figure 4a: Negative Earnings by Day of Week

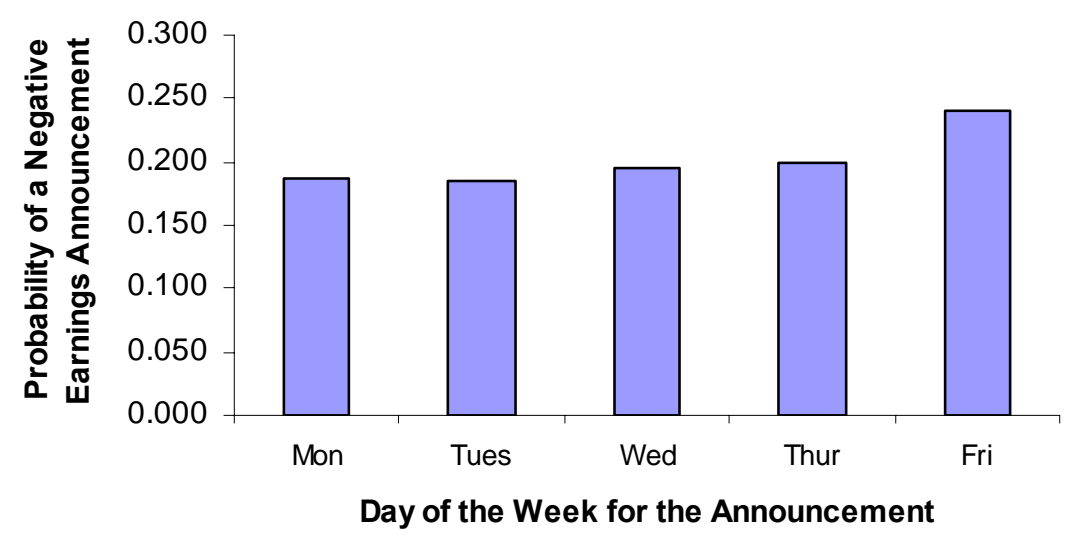

Figure 4b: Negative Earnings Surprise by Day of Week

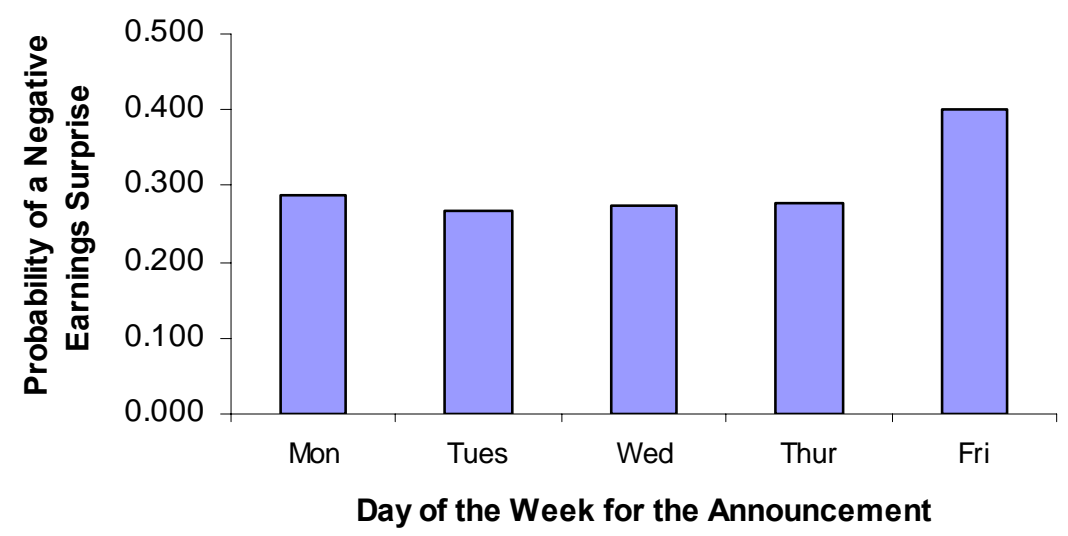

Figure 4c: Abnormal Return from 0 to 1 by Day of Week

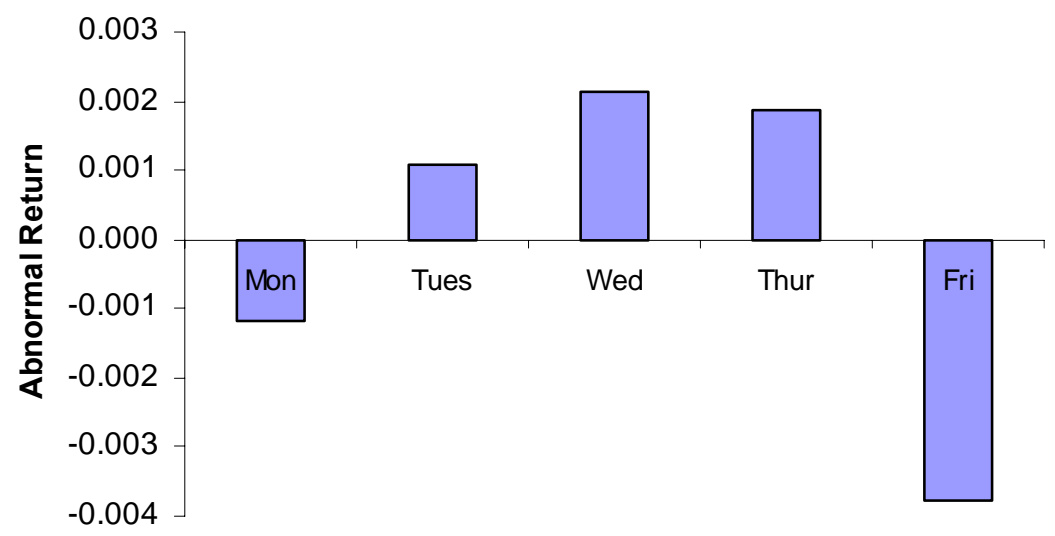

Day of the Week for the Announcement 
Figure 5: Histogram of Surprises By Quantile For Friday and Other Days

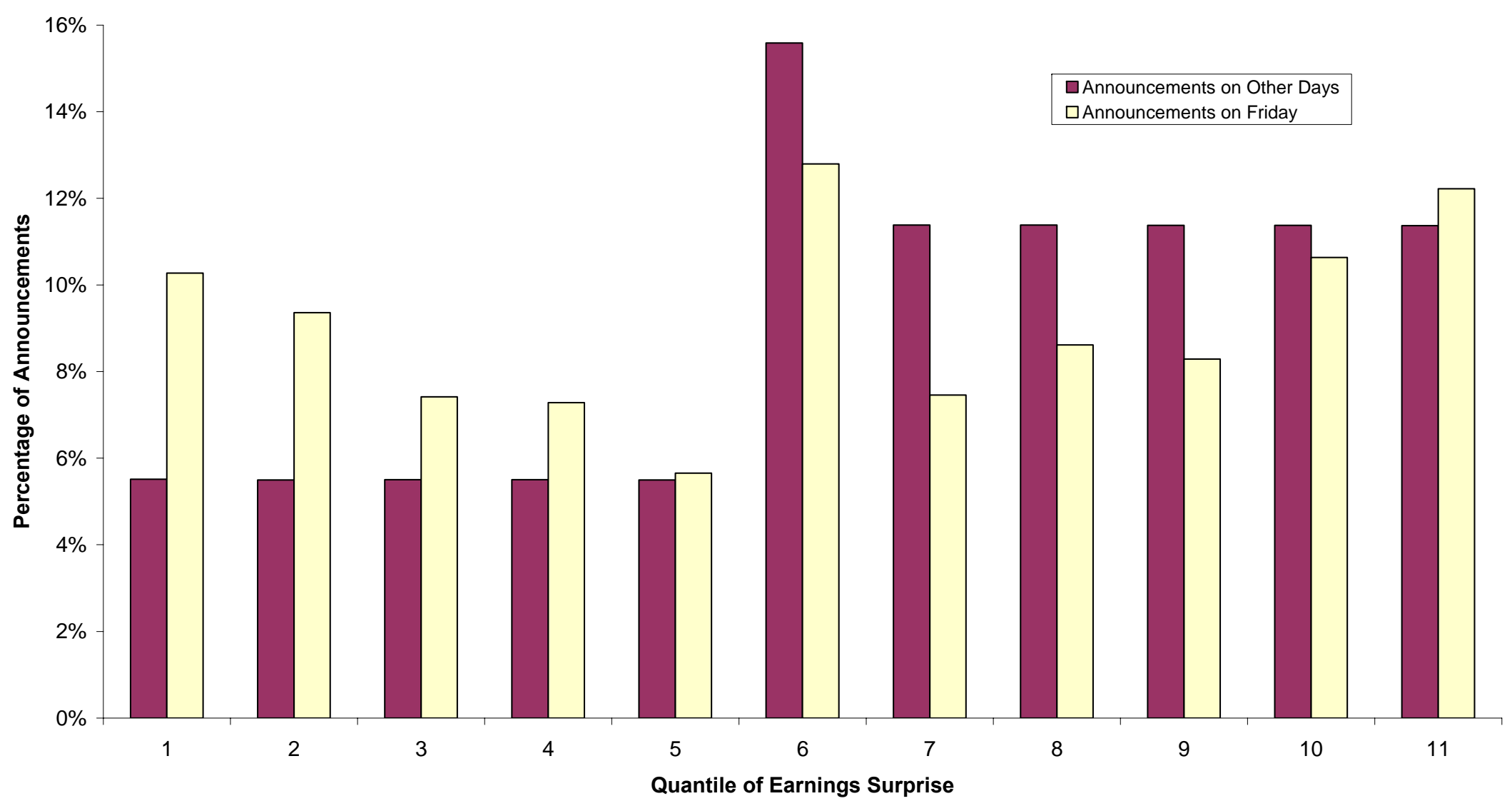

Notes: The earnings surprise for a particular quarterly announcement is the difference between actual earnings for the quarter recorded by $\mathrm{I} / \mathrm{B} / \mathrm{E} / \mathrm{S}$ and the median analyst forecast included in the I/B/E/S detail file during the 30 days before the quarterly earnings announcement scaled by the stock price 5 trading days before the announcement. Quantiles 1 through 5 contain earnings announcements for five quintiles of negative earnings surprises and quantiles 7 through 11 contain earnings surprises for 5 quintiles of positive earnings surprises. Quantile number 6 contains all announcements with an earnings surprise equal to zero. Since the number of negative earnings surprises, the number of surprises equal to zero, and the number of positive earnings surprises are not equal, the number of observations in each quantile must differ. The magnitudes are statistically different at the $1 \%$ level for quantiles $1,2,3,4,6,7,8$, and 9 . 
Table 1. Summary Statistics

\begin{tabular}{lcccccc}
\hline \hline \multicolumn{7}{c}{ Panel A: Distribution of Earnings Announcements by Day of the Week } \\
\hline & All & Monday & Tuesday & Wednesday & Thursday & Friday \\
\hline Number & 121381 & 17032 & 31022 & 30919 & 35421 & 6987 \\
Fraction & 1.0000 & 0.1403 & 0.2556 & 0.2547 & 0.2918 & 0.0576 \\
\hline
\end{tabular}

Panel B: Differences Between Announcements on Friday and Other Weekdays

\begin{tabular}{|c|c|c|c|c|c|c|c|}
\hline & \multicolumn{4}{|c|}{ Baseline Sample } & \multicolumn{3}{|c|}{ Homogeneous Sample } \\
\hline & All & Friday & Non-Friday & Difference & Friday & Non-Friday & Difference \\
\hline & $(1)$ & $(2)$ & (3) & $(4)$ & $(5)$ & (6) & $(7)$ \\
\hline Earnings surprise & $\begin{array}{l}-0.0013 \\
(0.0254)\end{array}$ & $\begin{array}{l}-0.0043 \\
(0.0382)\end{array}$ & $\begin{array}{l}-0.0011 \\
(0.0244)\end{array}$ & $\begin{array}{c}-0.0033 \\
(0.0005)^{\star \star \star}\end{array}$ & $\begin{array}{l}-0.0048 \\
(0.0404)\end{array}$ & $\begin{array}{l}-0.0017 \\
(0.0261)\end{array}$ & $\begin{array}{c}-0.0031 \\
(0.0006)^{\star \star \star}\end{array}$ \\
\hline Market Cap (\$M) & $\begin{array}{c}3248 \\
(14800)\end{array}$ & $\begin{array}{c}2440 \\
(12600)\end{array}$ & $\begin{array}{c}3297 \\
(14900)\end{array}$ & $\begin{array}{c}-857 \\
(157)^{\star \star \star}\end{array}$ & $\begin{array}{c}2397 \\
(13200)\end{array}$ & $\begin{array}{c}2467 \\
(15300)\end{array}$ & $\begin{array}{c}-70 \\
(215)\end{array}$ \\
\hline Year & $\begin{array}{c}1999.0460 \\
(2.6408)\end{array}$ & $\begin{array}{c}1998.5600 \\
(2.6328)\end{array}$ & $\begin{array}{c}1999.0760 \\
(2.6384)\end{array}$ & $\begin{array}{c}-0.5160 \\
(.0324)^{\star \star \star}\end{array}$ & $\begin{array}{c}1998.5680 \\
(2.6137)\end{array}$ & $\begin{array}{c}1998.7970 \\
(2.6283)\end{array}$ & $\begin{array}{c}-0.2290 \\
(.0410)^{\star \star \star}\end{array}$ \\
\hline Month 1 in Quarter & $\begin{array}{c}0.6233 \\
(0.4846)\end{array}$ & $\begin{array}{c}0.5801 \\
(0.4936)\end{array}$ & $\begin{array}{c}0.6259 \\
(0.4839)\end{array}$ & $\begin{array}{c}-0.0458 \\
(.0061)^{\star \star \star}\end{array}$ & $\begin{array}{c}0.5898 \\
(0.4919)\end{array}$ & $\begin{array}{c}0.6002 \\
(0.4899)\end{array}$ & $\begin{array}{l}-0.0104 \\
(0.0077)\end{array}$ \\
\hline Month 2 in Quarter & $\begin{array}{c}0.2949 \\
(0.4560)\end{array}$ & $\begin{array}{c}0.3152 \\
(0.4646)\end{array}$ & $\begin{array}{c}0.2936 \\
(0.4554)\end{array}$ & $\begin{array}{c}0.0215 \\
(.0057)^{\star \star \star}\end{array}$ & $\begin{array}{c}0.3138 \\
(0.4641)\end{array}$ & $\begin{array}{c}0.3089 \\
(0.4620)\end{array}$ & $\begin{array}{c}0.0049 \\
(0.0072)\end{array}$ \\
\hline Month 3 in Quarter & $\begin{array}{c}0.0819 \\
(0.2742)\end{array}$ & $\begin{array}{c}0.1048 \\
(0.3063)\end{array}$ & $\begin{array}{c}0.0805 \\
(0.2720)\end{array}$ & $\begin{array}{c}0.0243 \\
(.0037)^{\star \star \star}\end{array}$ & $\begin{array}{c}0.0965 \\
(0.2953)\end{array}$ & $\begin{array}{c}0.0910 \\
(0.2876)\end{array}$ & $\begin{array}{c}0.0055 \\
(0.0046)\end{array}$ \\
\hline Large Shareholder & $\begin{array}{c}0.6822 \\
(0.4656)\end{array}$ & $\begin{array}{c}0.6555 \\
(0.4753)\end{array}$ & $\begin{array}{c}0.6836 \\
(0.4651)\end{array}$ & $\begin{array}{c}-0.0281 \\
(.0089)^{\star \star \star}\end{array}$ & $\begin{array}{c}0.6569 \\
(0.4749)\end{array}$ & $\begin{array}{c}0.6646 \\
(0.4721)\end{array}$ & $\begin{array}{l}-0.0077 \\
(0.0117)\end{array}$ \\
\hline Entrenchment Index & $\begin{array}{c}9.0925 \\
(2.7462)\end{array}$ & $\begin{array}{c}9.1338 \\
(2.7479)\end{array}$ & $\begin{array}{c}9.0903 \\
(2.7461)\end{array}$ & $\begin{array}{c}0.0435 \\
(0.0565)\end{array}$ & $\begin{array}{c}8.9943 \\
(2.7801)\end{array}$ & $\begin{array}{c}9.0867 \\
(2.8188)\end{array}$ & $\begin{array}{l}-0.0924 \\
(0.0748)\end{array}$ \\
\hline $\mathbf{N}$ & $N=121381$ & $N=6987$ & $N=114394$ & $N=121381$ & $N=5192$ & $N=18630$ & $N=23822$ \\
\hline
\end{tabular}

Notes: In Columns 1-3 and 5-6 we present summary statistics, with standard deviations in parentheses. In Column 4 we present the difference between Columns 2 and 3 , with standard errors for the difference. In Column 7 we present the difference between Columns 5 and 6 , with standard errors for the difference. The homogeneous sample refers to announcements by companies that announced earnings both on Friday and other weekdays at least ten percent of the time. The indicator for a large shareholder is available for only 57,924 observations. The entrenchment index is available for only 48,500 observations. Publicly traded stocks in CRSP are matched to earnings announcements recorded in Compustat and I/B/E/S from the beginning of 1995 until June 2004. The earnings surprise for a quarterly announcement is the difference between actual earnings for the quarter recorded by I/B/E/S and the median analyst forecast included in the I/B/E/S detail file during the 30 days before the quarterly earnings announcement scaled by the stock price 5 trading days before the announcement.

* significant at $10 \%$; ** significant at $5 \%$; *** significant at $1 \%$ 
Table 2. Differential Response for the Top and Bottom Quantiles

Panel A: The Dependent Variable is the Cumulative Abnormal Return in Event Time From 0 to 1

\begin{tabular}{|c|c|c|c|c|c|c|}
\hline & $(1)$ & $(2)$ & (3) & (4) & $(5)$ & (6) \\
\hline Constant & $\begin{array}{c}-0.0365 \\
(0.0015)^{\star \star \star}\end{array}$ & 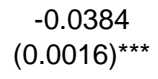 & $\begin{array}{c}-0.0332 \\
(0.0031)^{\star \star \star}\end{array}$ & $\begin{array}{c}-0.0328 \\
(0.0010)^{\star \star \star}\end{array}$ & $\begin{array}{c}-0.0238 \\
(0.0025)^{\star \star \star}\end{array}$ & $\begin{array}{c}-0.0302 \\
(0.0019)^{\star \star \star}\end{array}$ \\
\hline Friday & $\begin{array}{c}0.0053 \\
(0.0047)\end{array}$ & $\begin{array}{c}0.0035 \\
(0.0047)\end{array}$ & $\begin{array}{c}0.0030 \\
(0.0055)\end{array}$ & $\begin{array}{c}0.0035 \\
(0.0031)\end{array}$ & $\begin{array}{c}0.0018 \\
(0.0030)\end{array}$ & $\begin{array}{c}0.0031 \\
(0.0036)\end{array}$ \\
\hline Top Quantile & $\begin{array}{c}0.0659 \\
(0.0016)^{\star \star \star}\end{array}$ & $\begin{array}{c}0.0682 \\
(0.0017)^{\star \star \star}\end{array}$ & $\begin{array}{c}0.0595 \\
(0.0036)^{\star \star \star}\end{array}$ & & & \\
\hline (Top Quantile)*Friday & $\begin{array}{c}-0.0123 \\
(0.0054)^{\star \star}\end{array}$ & $\begin{array}{c}-0.0095 \\
(0.0055)^{\star}\end{array}$ & $\begin{array}{l}-0.0055 \\
(0.0067)\end{array}$ & & & \\
\hline Top Two Quantiles & & & & $\begin{array}{c}0.0578 \\
(0.0011)^{\star \star \star}\end{array}$ & $\begin{array}{c}0.0590 \\
(0.0011)^{\star \star \star}\end{array}$ & $\begin{array}{c}0.0511 \\
(0.0023)^{\star \star \star}\end{array}$ \\
\hline (Top Two Quantiles)*Friday & & & & $\begin{array}{c}-0.0109 \\
(0.0035)^{\star * *}\end{array}$ & $\begin{array}{c}-0.0087 \\
(0.0035)^{\star \star}\end{array}$ & $\begin{array}{c}-0.0062 \\
(0.0043)\end{array}$ \\
\hline Controls & & $x$ & $x$ & & $x$ & $\mathrm{X}$ \\
\hline Controls Interacted with Top (Two) & & $x$ & $x$ & & $x$ & $\mathrm{X}$ \\
\hline Homogenenous Sample & & & $x$ & & & $x$ \\
\hline $\mathbf{R}^{2}$ & 0.0797 & 0.0882 & 0.0910 & 0.0763 & 0.0820 & 0.0824 \\
\hline $\mathbf{N}$ & $N=20880$ & $N=20880$ & $N=5057$ & $N=41582$ & $N=41582$ & $N=9636$ \\
\hline
\end{tabular}

Panel B: The Dependent Variable is the Cumulative Abnormal Return in Event Time From 2 to 75

\begin{tabular}{|c|c|c|c|c|c|c|}
\hline & (1) & $(2)$ & (3) & (4) & (5) & (6) \\
\hline Constant & $\begin{array}{l}-0.0099 \\
(0.0074)\end{array}$ & $\begin{array}{l}-0.0068 \\
(0.0066)\end{array}$ & $\begin{array}{c}-0.0227 \\
(0.0108)^{\star \star}\end{array}$ & $\begin{array}{l}-0.0056 \\
(0.0052)\end{array}$ & $\begin{array}{c}0.0073 \\
(0.0048)\end{array}$ & $\begin{array}{c}-0.0156 \\
(0.0071)^{\star \star}\end{array}$ \\
\hline Friday & $\begin{array}{c}-0.0411 \\
(0.0179)^{\star *}\end{array}$ & $\begin{array}{c}-0.0293 \\
(0.0163)^{\star}\end{array}$ & $\begin{array}{c}-0.0301 \\
(0.0197)\end{array}$ & $\begin{array}{c}-0.0279 \\
(0.0118)^{\star \star}\end{array}$ & $\begin{array}{c}-0.0221 \\
(0.0110)^{\star \star}\end{array}$ & $\begin{array}{l}-0.0185 \\
(0.0133)\end{array}$ \\
\hline Top Quantile & $\begin{array}{c}0.0550 \\
(0.0072)^{\star \star \star}\end{array}$ & $\begin{array}{c}0.0523 \\
(0.0069)^{\star \star \star}\end{array}$ & $\begin{array}{c}0.0423 \\
(0.0130)^{\star \star \star}\end{array}$ & & & \\
\hline (Top Quantile)*Friday & $\begin{array}{c}0.0380 \\
(0.0185)^{\star \star}\end{array}$ & $\begin{array}{c}0.0327 \\
(0.0179)^{\star}\end{array}$ & $\begin{array}{c}0.0527 \\
(0.0220)^{\star \star}\end{array}$ & & & \\
\hline Top Two Quantiles & & & & $\begin{array}{c}0.0455 \\
(0.0045)^{\star \star \star}\end{array}$ & $\begin{array}{c}0.0437 \\
(0.0043)^{\star \star *}\end{array}$ & $\begin{array}{c}0.0394 \\
(0.0083)^{\star \star \star}\end{array}$ \\
\hline (Top Two Quantiles)Friday & & & & $\begin{array}{c}0.0261 \\
(0.0127)^{\star \star}\end{array}$ & $\begin{array}{c}0.0231 \\
(0.0127)^{\star}\end{array}$ & $\begin{array}{c}0.0307 \\
(0.0156)^{\star \star}\end{array}$ \\
\hline Controls & & $x$ & $x$ & & x & $x$ \\
\hline Controls Interacted with Top (Two) & & $x$ & $x$ & & $x$ & $x$ \\
\hline Homogenenous Sample & & & $x$ & & & $x$ \\
\hline $\mathbf{R}^{2}$ & 0.0047 & 0.0505 & 0.0540 & 0.0038 & 0.0394 & 0.0393 \\
\hline $\mathbf{N}$ & $N=20880$ & $N=20880$ & $N=5057$ & $N=41582$ & $N=41582$ & $N=9636$ \\
\hline
\end{tabular}

Notes: Publicly traded stocks in CRSP are matched to earnings announcements recorded in Compustat and I/B/E/S from the beginning of 1995 until June 2004 . In event time, day 0 is the day of the earnings announcement. The cumulative abnormal return for each stock is the raw buy-and-hold return adjusted using the estimated beta from the market model. The earnings surprise for a particular quarterly announcement is the difference between actual earnings for the quarter recorded by I/B/E/S and the median analyst forecast included in the I/B/E/S detail file during the 30 days before the quarterly earnings announcement scaled by the stock price 5 trading days before the announcement. Quantiles 1 through 5 contain earnings announcements for five quintiles of negative earnings surprises and quantiles 7 through 11 contain earnings surprises for 5 quintiles of positive earnings surprises. Quantile number 6 contains all announcements with an earnings surprise equal to zero. Since the number of negative earnings surprises, the number of surprises equal to zero, and the number of positive earnings surprises are not equal, the number of observations in each quantile differ.

Columns 1, 2, and 3 only include observations from the top quantile (11) and the bottom quantile (1). Columns 4, 5, and 6 only include observations from the top two quantiles (10 and 11 ) or the bottom two quantiles ( 1 and 2). The homogeneous sample refers to announcements by companies that announced earnings both on Friday and other weekdays at least ten percent of the time. The set of controls includes indicators for the year of announcement, the month of announcement, and the decile of a firm's market capitalization. Standard errors adjusted for heteroskedasticity and clustered by day of announcement are in parentheses.

* significant at $10 \%$; ** significant at $5 \%$; ** significant at $1 \%$ 
Table 2 (Continued). Differential Response for the Top and Bottom Quantiles

Panel C: The Dependent Variable is the Cumulative Abnormal Return in Event Time From 0 to 75

\begin{tabular}{|c|c|c|c|c|c|c|}
\hline & (1) & $(2)$ & (3) & (4) & (5) & (6) \\
\hline Constant & $\begin{array}{c}-0.0458 \\
(0.0074)^{\star \star \star}\end{array}$ & $\begin{array}{c}-0.0445 \\
(0.0065)^{\star \star \star}\end{array}$ & $\begin{array}{c}-0.0580 \\
(0.0105)^{\star \star \star}\end{array}$ & $\begin{array}{c}-0.0382 \\
(0.0052)^{\star \star \star}\end{array}$ & $\begin{array}{c}-0.0262 \\
(0.0049)^{\star \star \star}\end{array}$ & $\begin{array}{c}-0.0471 \\
(0.0071)^{\star \star \star}\end{array}$ \\
\hline Friday & $\begin{array}{c}-0.0360 \\
(0.0180)^{\star \star}\end{array}$ & $\begin{array}{l}-0.0255 \\
(0.0163)\end{array}$ & $\begin{array}{l}-0.0239 \\
(0.0199)\end{array}$ & $\begin{array}{c}-0.0247 \\
(0.0120)^{\star \star}\end{array}$ & $\begin{array}{c}-0.0202 \\
(0.0111)^{\star}\end{array}$ & $\begin{array}{c}-0.0131 \\
(0.0137)\end{array}$ \\
\hline Top Quantile & $\begin{array}{c}0.1256 \\
(0.0074)^{\star \star \star}\end{array}$ & $\begin{array}{c}0.1233 \\
(0.0072)^{\star \star \star}\end{array}$ & $\begin{array}{c}0.1048 \\
(0.0132)^{\star \star \star}\end{array}$ & & & \\
\hline (Top Quantile)*Friday & $\begin{array}{c}0.0224 \\
(0.0190)\end{array}$ & $\begin{array}{c}0.0201 \\
(0.0185)\end{array}$ & $\begin{array}{c}0.0437 \\
(0.0229)^{\star}\end{array}$ & & & \\
\hline Top Two Quantiles & & & & $\begin{array}{c}0.1071 \\
(0.0047)^{\star \star \star}\end{array}$ & $\begin{array}{c}0.1058 \\
(0.0045)^{\star \star \star}\end{array}$ & $\begin{array}{c}0.0940 \\
(0.0086)^{\star \star \star}\end{array}$ \\
\hline (Top Two Quantiles)^Friday & & & & $\begin{array}{c}0.0139 \\
(0.0132)\end{array}$ & $\begin{array}{c}0.0129 \\
(0.0132)\end{array}$ & $\begin{array}{c}0.0222 \\
(0.0163)\end{array}$ \\
\hline Controls & & $\mathrm{x}$ & $\mathrm{x}$ & & $x$ & $\mathrm{X}$ \\
\hline Controls Interacted with Top (Two) & & $x$ & $\mathrm{x}$ & & $x$ & $\mathrm{x}$ \\
\hline Homogenenous Sample & & & $x$ & & & $x$ \\
\hline $\mathbf{R}^{2}$ & 0.0185 & 0.0628 & 0.0663 & 0.0168 & 0.0510 & 0.0510 \\
\hline $\mathbf{N}$ & $N=20880$ & $N=20880$ & $N=5057$ & $N=41582$ & $N=41582$ & $N=9636$ \\
\hline
\end{tabular}

Panel D: Ratio of the Delayed Stock Response (2 to 75$)$ to the Long-term Stock Response (0 to 75)

\begin{tabular}{|c|c|c|c|c|c|c|}
\hline & (1) & $(2)$ & (3) & (4) & (5) & (6) \\
\hline $\begin{array}{l}\text { Response ratio for Friday } \\
\text { announcements }\end{array}$ & $\begin{array}{c}0.6287 \\
(0.0497)\end{array}$ & $\begin{array}{c}0.5866 \\
(0.0548)\end{array}$ & $\begin{array}{c}0.6361 \\
(0.0522)\end{array}$ & $\begin{array}{c}0.5922 \\
(0.0441)\end{array}$ & $\begin{array}{c}0.5597 \\
(0.0484)\end{array}$ & $\begin{array}{c}0.6046 \\
(0.0480)\end{array}$ \\
\hline $\begin{array}{l}\text { Response ratio for announcements } \\
\text { on other days }\end{array}$ & $\begin{array}{c}0.4380 \\
(0.0335)\end{array}$ & $\begin{array}{c}0.4188 \\
(0.0334)\end{array}$ & $\begin{array}{c}0.4003 \\
(0.0774)\end{array}$ & $\begin{array}{c}0.4252 \\
(0.0251)\end{array}$ & $\begin{array}{c}0.4109 \\
(0.0244)\end{array}$ & $\begin{array}{c}0.4205 \\
(0.0540)\end{array}$ \\
\hline $\begin{array}{l}\text { Difference between the response } \\
\text { ratio for Friday and other days }\end{array}$ & $\begin{array}{c}0.1907 \\
(0.0599)^{\star \star \star}\end{array}$ & $\begin{array}{c}0.1678 \\
(0.0627)^{\star \star \star}\end{array}$ & $\begin{array}{c}0.2357 \\
(0.0913)^{\star \star \star}\end{array}$ & $\begin{array}{c}0.1670 \\
(0.0507)^{\star \star \star}\end{array}$ & $\begin{array}{c}0.1489 \\
(0.0536)^{\star \star \star}\end{array}$ & $\begin{array}{c}0.1841 \\
(0.0723)^{\star \star}\end{array}$ \\
\hline Controls & & $x$ & $x$ & & $x$ & $x$ \\
\hline Controls Interacted with Top (Two) & & $\mathrm{X}$ & $\mathrm{X}$ & & $\mathrm{X}$ & $x$ \\
\hline Homogenenous Sample & & & $x$ & & & $x$ \\
\hline $\mathbf{N}$ & $N=20880$ & $N=20880$ & $N=5057$ & $N=41582$ & $N=41582$ & $N=9636$ \\
\hline
\end{tabular}

Notes: Publicly traded stocks in CRSP are matched to earnings announcements recorded in Compustat and I/B/E/S from the beginning of 1995 until June 2004 . In event time, day 0 is the day of the earnings announcement. The cumulative abnormal return for each stock is the raw buy-and-hold return adjusted using the estimated beta from the market model. The earnings surprise for a particular quarterly announcement is the difference between actual earnings for the quarter recorded by I/B/E/S and the median analyst forecast included in the I/B/E/S detail file during the 30 days before the quarterly earnings announcement scaled by the stock price 5 trading days before the announcement. Quantiles 1 through 5 contain earnings announcements for five quintiles of negative earnings surprises and quantiles 7 through 11 contain earnings surprises for 5 quintiles of positive earnings surprises. Quantile number 6 contains all announcements with an earnings surprise equal to zero. Since the number of negative earnings surprises, the number of surprises equal to zero, and the number of positive earnings surprises are not equal, the number of observations in each quantile differ.

Columns 1, 2, and 3 only include observations from the top quantile (11) and the bottom quantile (1). Columns 4, 5 , and 6 only include observations from the top two quantiles (10 and 11 ) or the bottom two quantiles ( 1 and 2). The Response Ratios in Panel D are computed as the ratio of the Top-to-Bottom Return (2 to 75) from Table 2B and the Top-to-Bottom Return (0 to 75) from Table $2 \mathrm{C}$. The homogeneous sample refers to announcements by companies that announced earnings both on Friday and other weekdays at least ten percent of the time. The set of controls includes indicators for the year of announcement, the month of announcement, and the decile of a firm's market capitalization. Standard errors adjusted for heteroskedasticity and clustered by day of announcement are in parentheses.

* significant at $10 \%$; ** significant at $5 \%$; *** significant at $1 \%$ 
Table 3. Short-term Stock Price Response to an Earnings Announcement

\begin{tabular}{|c|c|c|c|c|c|c|c|}
\hline \multicolumn{8}{|c|}{ Dependent Variable: Cumulative Abnormal Return in Event Time from 0 to 1} \\
\hline & (1) & $(2)$ & (3) & $(4)$ & (5) & $(6)$ & (7) \\
\hline Constant & $\begin{array}{c}-0.0060 \\
(0.0007)^{\star \star \star}\end{array}$ & $\begin{array}{c}-0.0040 \\
(0.0006)^{\star \star \star}\end{array}$ & $\begin{array}{c}-0.0040 \\
(0.0006)^{\star \star \star}\end{array}$ & $\begin{array}{c}-0.0017 \\
(0.0007)^{\star \star}\end{array}$ & $\begin{array}{c}-0.0031 \\
(0.0012)^{\star \star}\end{array}$ & $\begin{array}{c}-0.0038 \\
(0.0006)^{\star \star \star}\end{array}$ & $\begin{array}{l}-0.0028 \\
(0.0011)^{\star \star}\end{array}$ \\
\hline Earnings Surprise Quantile 1 & $\begin{array}{l}-0.0306 \\
(0.0015)^{\star \star \star}\end{array}$ & $\begin{array}{c}-0.0223 \\
(0.0019)^{\star \star \star}\end{array}$ & $\begin{array}{c}-0.0220 \\
(0.0020)^{\star \star *}\end{array}$ & & $\begin{array}{c}-0.0270 \\
(0.0045)^{\star \star \star}\end{array}$ & $\begin{array}{c}-0.0181 \\
(0.0018)^{\star \star *}\end{array}$ & $\begin{array}{c}-0.0235 \\
(0.0043)^{\star \star *}\end{array}$ \\
\hline Earnings Surprise Quantile 2 & $\begin{array}{c}-0.0234 \\
(0.0013)^{\star \star \star}\end{array}$ & $\begin{array}{c}-0.0158 \\
(0.0015)^{\star \star \star}\end{array}$ & $\begin{array}{c}-0.0155 \\
(0.0015)^{\star \star \star}\end{array}$ & & $\begin{array}{c}-0.0237 \\
(0.0040)^{\star \star \star}\end{array}$ & $\begin{array}{c}-0.0118 \\
(0.0013)^{\star \star \star}\end{array}$ & $\begin{array}{c}-0.0148 \\
(0.0031)^{\star \star \star}\end{array}$ \\
\hline Earnings Surprise Quantile 3 & $\begin{array}{c}-0.0149 \\
(0.0011)^{\star \star \star}\end{array}$ & $\begin{array}{c}-0.0099 \\
(0.0011)^{\star \star \star}\end{array}$ & $\begin{array}{c}-0.0098 \\
(0.0011)^{\star \star \star}\end{array}$ & & $\begin{array}{c}-0.0123 \\
(0.0027)^{\star \star \star}\end{array}$ & $\begin{array}{c}-0.0088 \\
(0.0011)^{\star \star \star}\end{array}$ & $\begin{array}{c}-0.0081 \\
(0.0023)^{\star \star \star}\end{array}$ \\
\hline Earnings Surprise Quantile 4 & $\begin{array}{c}-0.0105 \\
(0.0011)^{\star \star \star}\end{array}$ & $\begin{array}{c}-0.0066 \\
(0.0009)^{\star \star \star}\end{array}$ & $\begin{array}{c}-0.0066 \\
(0.0009)^{\star \star \star}\end{array}$ & & $\begin{array}{c}-0.0065 \\
(0.0021)^{\star \star \star}\end{array}$ & $\begin{array}{c}-0.0051 \\
(0.0008)^{\star \star \star}\end{array}$ & $\begin{array}{c}-0.0050 \\
(0.0020)^{\star \star \star}\end{array}$ \\
\hline Earnings Surprise Quantile 5 & $\begin{array}{c}-0.0075 \\
(0.0010)^{\star \star \star}\end{array}$ & $\begin{array}{c}-0.0048 \\
(0.0008)^{\star \star \star}\end{array}$ & $\begin{array}{c}-0.0047 \\
(0.0008)^{\star \star \star}\end{array}$ & & $\begin{array}{c}-0.0048 \\
(0.0020)^{\star \star}\end{array}$ & $\begin{array}{c}-0.0044 \\
(0.0008)^{\star \star \star}\end{array}$ & $\begin{array}{c}-0.0053 \\
(0.0020)^{\star \star \star *}\end{array}$ \\
\hline Earnings Surprise Quantile 7 & $\begin{array}{c}0.0067 \\
(0.0009)^{\star \star \star}\end{array}$ & $\begin{array}{c}0.0043 \\
(0.0007)^{\star \star \star}\end{array}$ & $\begin{array}{c}0.0043 \\
(0.0007)^{\star \star \star}\end{array}$ & & $\begin{array}{c}0.0032 \\
(0.0017)^{\star}\end{array}$ & $\begin{array}{c}0.0040 \\
(0.0006)^{\star \star \star}\end{array}$ & $\begin{array}{c}0.0022 \\
(0.0015)\end{array}$ \\
\hline Earnings Surprise Quantile 8 & $\begin{array}{c}0.0157 \\
(0.0009)^{\star * *}\end{array}$ & $\begin{array}{c}0.0101 \\
(0.0010)^{\star \star \star}\end{array}$ & $\begin{array}{c}0.0100 \\
(0.0010)^{\star \star *}\end{array}$ & & $\begin{array}{c}0.0100 \\
(0.0022)^{\star \star \star}\end{array}$ & $\begin{array}{c}0.0091 \\
(0.0010)^{\star * *}\end{array}$ & $\begin{array}{c}0.0084 \\
(0.0020)^{\star * *}\end{array}$ \\
\hline Earnings Surprise Quantile 9 & $\begin{array}{c}0.0215 \\
(0.0009)^{\star \star \star}\end{array}$ & $\begin{array}{c}0.0137 \\
(0.0013)^{\star \star \star}\end{array}$ & $\begin{array}{c}0.0135 \\
(0.0013)^{\star \star \star}\end{array}$ & & $\begin{array}{c}0.0143 \\
(0.0027)^{\star \star \star}\end{array}$ & $\begin{array}{c}0.0128 \\
(0.0013)^{\star \star \star}\end{array}$ & $\begin{array}{c}0.0121 \\
(0.0026)^{\star \star \star}\end{array}$ \\
\hline Earnings Surprise Quantile 10 & $\begin{array}{c}0.0264 \\
(0.0009)^{\star \star \star}\end{array}$ & $\begin{array}{c}0.0169 \\
(0.0015)^{\star \star \star}\end{array}$ & $\begin{array}{c}0.0166 \\
(0.0016)^{\star \star \star}\end{array}$ & & $\begin{array}{c}0.0148 \\
(0.0028)^{\star \star \star}\end{array}$ & $\begin{array}{c}0.0155 \\
(0.0016)^{\star \star \star}\end{array}$ & $\begin{array}{c}0.0142 \\
(0.0029)^{\star \star \star}\end{array}$ \\
\hline Earnings Surprise Quantile 11 & $\begin{array}{c}0.0354 \\
(0.0011)^{\star * *}\end{array}$ & $\begin{array}{c}0.0229 \\
(0.0020)^{\star \star \star}\end{array}$ & $\begin{array}{c}0.0225 \\
(0.0021)^{\star * *}\end{array}$ & & $\begin{array}{c}0.0262 \\
(0.0044)^{\star * *}\end{array}$ & $\begin{array}{c}0.0203 \\
(0.0020)^{\star * *}\end{array}$ & $\begin{array}{c}0.0196 \\
(0.0037)^{\star * *}\end{array}$ \\
\hline Arctan Coefficient: $\varphi_{1}$ & & & & $\begin{array}{c}714.4450 \\
(40.4694)^{\star \star \star}\end{array}$ & & & \\
\hline Arctan Coefficient: $\varphi_{2}$ & & & & $\begin{array}{c}0.0135 \\
(0.0011)^{\star \star \star}\end{array}$ & & & \\
\hline Arctan Coefficient: $\varphi_{\text {pos }}$ & & & & $\begin{array}{c}0.2224 \\
(0.0688)^{\star \star \star}\end{array}$ & & & \\
\hline $\begin{array}{l}\text { Friday } \\
\text { (Proportional Effect) }\end{array}$ & $\begin{array}{c}-0.1874 \\
(0.0514)^{\star \star \star}\end{array}$ & $\begin{array}{c}-0.1633 \\
(0.0530)^{\star \star \star}\end{array}$ & $\begin{array}{c}-0.1477 \\
(0.0584)^{\star \star}\end{array}$ & $\begin{array}{c}-0.1552 \\
(0.0517)^{\star \star \star}\end{array}$ & $\begin{array}{l}-0.1252 \\
(0.0737)^{\star}\end{array}$ & $\begin{array}{c}-0.2094 \\
(0.0503)^{\star \star \star}\end{array}$ & $\begin{array}{c}-0.1774 \\
(0.0727)^{\star \star}\end{array}$ \\
\hline $\begin{array}{l}\text { Monday } \\
\text { (Proportional Effect) }\end{array}$ & & & $\begin{array}{c}0.0440 \\
(0.0511)\end{array}$ & & & & \\
\hline $\begin{array}{l}\text { Tuesday } \\
\text { (Proportional Effect) }\end{array}$ & & & $\begin{array}{c}0.0536 \\
(0.0445)\end{array}$ & & & & \\
\hline $\begin{array}{l}\text { Thursday } \\
\text { (Proportional Effect) }\end{array}$ & & & $\begin{array}{l}-0.0066 \\
(0.0445)\end{array}$ & & & & \\
\hline Controls & & $\mathrm{X}$ & $\mathrm{x}$ & $x$ & $x$ & $x$ & $x$ \\
\hline Arctan Specification & & & & $x$ & & & \\
\hline Homogeneous Sample & & & & & $x$ & & $x$ \\
\hline Abs(Earnings Surprise) $<.02$ & & & & & & $x$ & $x$ \\
\hline $\mathbf{R}^{2}$ & 0.0514 & 0.0530 & 0.0530 & 0.0548 & 0.0528 & 0.0487 & 0.0510 \\
\hline $\mathbf{N}$ & $N=121381$ & $N=121381$ & $N=121381$ & $N=121381$ & $N=23822$ & $N=114894$ & $N=21453$ \\
\hline
\end{tabular}

Notes: Publicly traded stocks in CRSP are matched to earnings announcements recorded in Compustat and l/B/E/S from the beginning of 1995 until June 2004 . In event time, day 0 is the day of the earnings announcement. The cumulative abnormal return for each stock is the raw buy-and-hold return adjusted using the estimated beta from market model. The earnings surprise for a particular quarterly announcement is the difference between actual earnings for the quarter recorded by I/B/E/S and the median analyst forecast included in the $\mathrm{I} / \mathrm{B} / \mathrm{E} / \mathrm{S}$ detail file during the 30 days before the quarterly earnings announcement scaled by the stock price 5 trading days before the announcement.

The homogeneous sample refers to announcements by companies that announced earnings both on Friday and other weekdays at least ten percent of the time. The controls enter the non-linear regression in a proportional fashion. The set of controls includes indicators for the year of announcement, the month of announcement, and the decile of a firm's market capitalization Announcements made on Saturday or Sunday are excluded from the sample. Standard errors adjusted for heteroskedasticity and clustered by day of announcement are in parentheses.

* significant at $10 \%$; ** significant at $5 \%$; *** significant at $1 \%$ 
Table 4. Short-term Volume Response to an Earnings Announcement

Dependent Variable: Abnormal Volume in Event Time from 0 to 1

\begin{tabular}{|c|c|c|c|c|c|c|c|}
\hline & (1) & (2) & (3) & (4) & (5) & (6) & (7) \\
\hline Constant & $\begin{array}{c}0.4393 \\
(0.0085)^{\star \star \star}\end{array}$ & $\begin{array}{c}0.6695 \\
(0.0241)^{\star \star \star}\end{array}$ & $\begin{array}{c}0.4295 \\
(0.0289)^{\star \star \star}\end{array}$ & $\begin{array}{c}0.4332 \\
(0.0299)^{\star \star \star}\end{array}$ & $\begin{array}{c}0.5707 \\
(0.0221)^{\star \star \star}\end{array}$ & $\begin{array}{c}0.3869 \\
(0.0274)^{\star \star \star}\end{array}$ & $\begin{array}{c}0.3285 \\
(0.0528)^{\star \star \star}\end{array}$ \\
\hline Earnings Surprise Quantile 1 & $\begin{array}{c}0.1382 \\
(0.0143)^{\star \star \star}\end{array}$ & $\begin{array}{c}0.0793 \\
(0.0145)^{\star \star \star}\end{array}$ & $\begin{array}{c}0.1835 \\
(0.0161)^{\star \star \star}\end{array}$ & $\begin{array}{c}0.1839 \\
(0.0161)^{\star \star \star}\end{array}$ & $\begin{array}{c}0.2130 \\
(0.0328)^{\star \star \star}\end{array}$ & $\begin{array}{c}0.1850 \\
(0.0161)^{\star \star \star}\end{array}$ & $\begin{array}{c}0.2114 \\
(0.0327)^{\star \star \star}\end{array}$ \\
\hline Earnings Surprise Quantile 2 & $\begin{array}{c}0.0964 \\
(0.0133)^{\star \star \star}\end{array}$ & $\begin{array}{c}0.0619 \\
(0.0131)^{\star \star \star}\end{array}$ & $\begin{array}{c}0.1689 \\
(0.0137)^{\star \star \star}\end{array}$ & $\begin{array}{c}0.1693 \\
(0.0138)^{\star \star \star}\end{array}$ & $\begin{array}{c}0.2131 \\
(0.0305)^{\star \star \star}\end{array}$ & $\begin{array}{c}0.1699 \\
(0.0137)^{\star \star \star}\end{array}$ & $\begin{array}{c}0.2125 \\
(0.0304)^{\star \star \star}\end{array}$ \\
\hline Earnings Surprise Quantile 3 & $\begin{array}{c}0.0556 \\
(0.0132)^{\star \star \star}\end{array}$ & $\begin{array}{c}0.0345 \\
(0.0131)^{\star \star \star}\end{array}$ & $\begin{array}{c}0.1343 \\
(0.0136)^{\star \star \star}\end{array}$ & $\begin{array}{c}0.1345 \\
(0.0136)^{\star \star \star}\end{array}$ & $\begin{array}{c}0.1519 \\
(0.0296)^{\star \star \star}\end{array}$ & $\begin{array}{c}0.1353 \\
(0.0135)^{\star \star \star}\end{array}$ & $\begin{array}{c}0.1509 \\
(0.0295)^{\star \star \star}\end{array}$ \\
\hline Earnings Surprise Quantile 4 & $\begin{array}{c}0.0345 \\
(0.0120)^{\star \star \star}\end{array}$ & $\begin{array}{c}0.0257 \\
(0.0118)^{\star \star}\end{array}$ & $\begin{array}{c}0.1040 \\
(0.0121)^{\star \star \star}\end{array}$ & $\begin{array}{c}0.1041 \\
(0.0121)^{\star \star \star}\end{array}$ & $\begin{array}{c}0.0414 \\
(0.0283)\end{array}$ & $\begin{array}{c}0.1066 \\
(0.0121)^{\star \star \star}\end{array}$ & $\begin{array}{c}0.0425 \\
(0.0282)\end{array}$ \\
\hline Earnings Surprise Quantile 5 & $\begin{array}{c}0.0073 \\
(0.0117)\end{array}$ & $\begin{array}{c}0.0134 \\
(0.0115)\end{array}$ & $\begin{array}{c}0.0675 \\
(0.0117)^{\star \star \star}\end{array}$ & $\begin{array}{c}0.0676 \\
(0.0117)^{\star \star \star}\end{array}$ & $\begin{array}{c}0.0423 \\
(0.0293)\end{array}$ & $\begin{array}{c}0.0702 \\
(0.0117)^{\star \star \star}\end{array}$ & $\begin{array}{c}0.0466 \\
(0.0293)\end{array}$ \\
\hline Earnings Surprise Quantile 7 & $\begin{array}{c}0.0215 \\
(0.0091)^{\star \star}\end{array}$ & $\begin{array}{c}0.0445 \\
(0.0087)^{\star \star \star}\end{array}$ & $\begin{array}{l}-0.0077 \\
(0.0085)\end{array}$ & $\begin{array}{l}-0.0078 \\
(0.0086)\end{array}$ & $\begin{array}{l}-0.0101 \\
(0.0243)\end{array}$ & $\begin{array}{l}-0.0045 \\
(0.0085)\end{array}$ & $\begin{array}{l}-0.0061 \\
(0.0244)\end{array}$ \\
\hline Earnings Surprise Quantile 8 & $\begin{array}{c}0.0492 \\
(0.0094)^{\star \star \star}\end{array}$ & $\begin{array}{c}0.0608 \\
(0.0091)^{\star \star \star}\end{array}$ & $\begin{array}{c}0.0245 \\
(0.0094)^{\star \star \star}\end{array}$ & $\begin{array}{c}0.0248 \\
(0.0094)^{\star \star \star}\end{array}$ & $\begin{array}{c}0.0140 \\
(0.0254)\end{array}$ & $\begin{array}{c}0.0263 \\
(0.0093)^{\star \star \star}\end{array}$ & $\begin{array}{c}0.0153 \\
(0.0255)\end{array}$ \\
\hline Earnings Surprise Quantile 9 & $\begin{array}{c}0.0842 \\
(0.0093)^{\star \star \star}\end{array}$ & $\begin{array}{c}0.0889 \\
(0.0091)^{\star \star \star}\end{array}$ & $\begin{array}{c}0.0939 \\
(0.0093)^{\star \star \star}\end{array}$ & $\begin{array}{c}0.0938 \\
(0.0093)^{\star \star \star}\end{array}$ & $\begin{array}{c}0.0694 \\
(0.0245)^{\star \star \star}\end{array}$ & $\begin{array}{c}0.0945 \\
(0.0093)^{\star \star \star}\end{array}$ & $\begin{array}{c}0.0696 \\
(0.0244)^{\star \star \star}\end{array}$ \\
\hline Earnings Surprise Quantile 10 & $\begin{array}{c}0.1353 \\
(0.0100)^{\star \star \star}\end{array}$ & $\begin{array}{c}0.1318 \\
(0.0098)^{\star \star \star}\end{array}$ & $\begin{array}{c}0.1745 \\
(0.0103)^{\star \star \star}\end{array}$ & $\begin{array}{c}0.1744 \\
(0.0103)^{\star \star \star}\end{array}$ & $\begin{array}{c}0.1668 \\
(0.0255)^{\star \star \star}\end{array}$ & $\begin{array}{c}0.1755 \\
(0.0103)^{\star \star \star}\end{array}$ & $\begin{array}{c}0.1683 \\
(0.0254)^{\star \star \star}\end{array}$ \\
\hline Earnings Surprise Quantile 11 & $\begin{array}{c}0.2248 \\
(0.0106)^{\star \star \star}\end{array}$ & $\begin{array}{c}0.2027 \\
(0.0103)^{\star \star \star}\end{array}$ & $\begin{array}{c}0.3060 \\
(0.0111)^{\star \star \star}\end{array}$ & $\begin{array}{c}0.3061 \\
(0.0111)^{\star \star \star}\end{array}$ & $\begin{array}{c}0.3133 \\
(0.0261)^{\star \star \star}\end{array}$ & $\begin{array}{c}0.3064 \\
(0.0110)^{\star \star \star}\end{array}$ & $\begin{array}{c}0.3122 \\
(0.0260)^{\star \star \star}\end{array}$ \\
\hline Friday & $\begin{array}{c}-0.1052 \\
(0.0174)^{\star \star \star}\end{array}$ & $\begin{array}{c}-0.1243 \\
(0.0146)^{\star \star \star}\end{array}$ & $\begin{array}{c}-0.0480 \\
(0.0148)^{\star \star \star}\end{array}$ & $\begin{array}{c}-0.0521 \\
(0.0167)^{\star \star \star}\end{array}$ & $\begin{array}{c}-0.0669 \\
(0.0167)^{\star \star \star}\end{array}$ & $\begin{array}{l}-0.0214 \\
(0.0139)\end{array}$ & $\begin{array}{c}-0.0432 \\
(0.0162)^{\star \star \star}\end{array}$ \\
\hline Monday & & & & $\begin{array}{c}0.0116 \\
(0.0146)\end{array}$ & & & \\
\hline Tuesday & & & & $\begin{array}{c}0.0188 \\
(0.0125)\end{array}$ & & & \\
\hline Thursday & & & & $\begin{array}{c}-0.0308 \\
(0.0129)^{\star \star}\end{array}$ & & & \\
\hline Aggregate Abnormal Volume & & & & & & $\begin{array}{c}0.3956 \\
(0.0319)^{\star \star \star}\end{array}$ & $\begin{array}{c}0.3457 \\
(0.0412)^{\star \star \star}\end{array}$ \\
\hline Controls & & $x$ & $x$ & $x$ & $x$ & $x$ & $x$ \\
\hline Company Fixed Effects & & & $x$ & $\mathrm{x}$ & $x$ & $x$ & $x$ \\
\hline Homogeneous Sample & & & & & $x$ & & $x$ \\
\hline $\mathbf{R}^{2}$ & 0.0072 & 0.0297 & 0.1897 & 0.1901 & 0.1956 & 0.1958 & 0.1996 \\
\hline $\mathbf{N}$ & $N=121179$ & $N=121179$ & $N=121179$ & $N=121179$ & $N=23735$ & $N=121179$ & $N=23735$ \\
\hline
\end{tabular}

Notes: Publicly traded stocks in CRSP are matched to earnings announcements recorded in Compustat and I/B/E/S from the beginning of 1995 until June 2004. In event time, day 0 is the day of the earnings announcement. The abnormal volume for each stock is the average log volume on the day of and the day after the announcement, divided by the average log volume for the period -20 to - -11 in event time (10 trading days). The earnings surprise for a particular quarterly announcement is the difference between actual earnings for the quarter recorded by $/ / \mathrm{B} / \mathrm{E} / \mathrm{S}$ and the median analyst forecast included in the $\mathrm{I} / \mathrm{B} / \mathrm{E} / \mathrm{S}$ detail file during the 30 days before the quarterly earnings announcement scaled by the stock price 5 trading days before the announcement.

The homogeneous sample refers to announcements by companies that announced earnings both on Friday and other weekdays at least ten percent of the time. The set of controls includes indicators for the year of announcement, the month of announcement, and the decile of a firm's market capitalization. Announcements made on Saturday or Sunday are excluded from the sample. Standard errors adjusted for heteroskedasticity and clustered by day of announcement are in parentheses.

* significant at $10 \%$; ** significant at $5 \%$; *** significant at $1 \%$ 
Table 5. Firm Timing of Earnings Announcements (Odds Ratios)

\begin{tabular}{|c|c|c|c|c|c|}
\hline \multicolumn{6}{|c|}{ Panel A: The Dependent Variable is an Indicator for Negative Earnings } \\
\hline & (1) & $(2)$ & (3) & (4) & (5) \\
\hline Friday & $\begin{array}{c}1.3275 \\
(0.0738)^{\star \star \star}\end{array}$ & $\begin{array}{c}1.2504 \\
(0.0551)^{\star \star \star}\end{array}$ & $\begin{array}{c}1.7597 \\
(0.0948)^{\star \star \star}\end{array}$ & $\begin{array}{c}1.8122 \\
(0.1077)^{\star \star \star}\end{array}$ & $\begin{array}{c}1.6178 \\
(0.1050)^{\star \star \star}\end{array}$ \\
\hline Monday & & & & $\begin{array}{c}1.0149 \\
(0.0480)\end{array}$ & \\
\hline Tuesday & & & & $\begin{array}{c}0.9929 \\
(0.0396)\end{array}$ & \\
\hline Thursday & & & & $\begin{array}{c}1.0881 \\
(0.0428)^{\star \star}\end{array}$ & \\
\hline Controls & & $x$ & $x$ & $x$ & $x$ \\
\hline Company Fixed Effects & & & $x$ & $x$ & $x$ \\
\hline Homogeneous Friday Sample & & & & & $x$ \\
\hline Specification & Logit & Logit & Cond. Logit & Cond. Logit & Cond. Logit \\
\hline Baseline of Dep. Var. & 0.1949 & 0.1949 & 0.2862 & 0.2862 & 0.2981 \\
\hline $\mathbf{N}$ & $N=121381$ & $N=121381$ & $N=60037$ & $N=60037$ & $N=11779$ \\
\hline \multicolumn{6}{|c|}{ Panel B: The Dependent Variable is an Indicator for Negative Earnings Surprise } \\
\hline & $(1)$ & $(2)$ & (3) & (4) & (5) \\
\hline Friday & $\begin{array}{c}1.7548 \\
(0.0578)^{\star \star \star}\end{array}$ & $\begin{array}{c}1.6007 \\
(0.0446)^{\star \star \star}\end{array}$ & $\begin{array}{c}1.3646 \\
(0.0439)^{\star \star \star}\end{array}$ & $\begin{array}{c}1.3812 \\
(0.0489)^{\star \star \star}\end{array}$ & $\begin{array}{c}1.3661 \\
(0.0529)^{\star \star \star}\end{array}$ \\
\hline Monday & & & & $\begin{array}{c}1.0099 \\
(0.0280)\end{array}$ & \\
\hline Tuesday & & & & $\begin{array}{c}0.9979 \\
(0.0226)\end{array}$ & \\
\hline Thursday & & & & $\begin{array}{c}1.0326 \\
(0.0232)\end{array}$ & \\
\hline Controls & & $\mathrm{x}$ & $x$ & $x$ & $x$ \\
\hline Company Fixed Effects & & & $x$ & $x$ & $x$ \\
\hline Homogeneous Sample & & & & & $x$ \\
\hline Specification & Logit & Logit & Cond. Logit & Cond. Logit & Cond. Logit \\
\hline Baseline of Dep. Var. & 0.2824 & 0.2824 & 0.2919 & 0.2919 & 0.3555 \\
\hline $\mathbf{N}$ & $N=121381$ & $N=121381$ & $N=113424$ & $N=113424$ & $N=22771$ \\
\hline
\end{tabular}

Notes: Estimates from logit and conditional logit regressions are reported with robust standard errors in parentheses. The standard errors are clustered by day of announcement for the logit specifications, but not for the conditional logit. Publicly traded stocks in CRSP are matched to earnings announcements recorded in Compustat and I/B/E/S from the beginning of 1995 until June 2004. In event time, day 0 is the day of the earnings announcement. Measures of actual and forecasted earnings per share are extracted from I/B/E/S. The earnings surprise for a particular quarterly announcement is the difference between actual earnings per share for the quarter and the median analyst forecast included in the I/B/E/S detail file during the 30 days before the quarterly earnings announcement scaled by the stock price 5 trading days before the announcement.

The homogeneous sample refers to announcements by companies that announced earnings both on Friday and other weekdays at least ten percent of the time. The set of controls includes indicators for the year of announcement, the month of announcement, and the decile of a firm's market capitalization. Announcements made on Saturday or Sunday are excluded from the sample. The conditional logit specifications have fewer observations because any company for which the dependent variable does not vary over time is automatically dropped from the sample.

* significant at $10 \%$; ** significant at $5 \%$; *** significant at $1 \%$ 
Table 5 (Continued). Firm Timing of Earnings Announcements

\begin{tabular}{|c|c|c|c|c|c|}
\hline \multicolumn{6}{|c|}{ Panel C: The Dependent Variable is the Abnormal Stock Return from 0 to 1} \\
\hline & (1) & (2) & (3) & $(4)$ & (5) \\
\hline Constant & $\begin{array}{c}0.0013 \\
(0.0004)^{\star \star \star}\end{array}$ & $\begin{array}{c}0.0024 \\
(0.0016)\end{array}$ & $\begin{array}{c}0.0310 \\
(0.0025)^{\star \star \star}\end{array}$ & $\begin{array}{c}0.0321 \\
(0.0027)^{\star \star \star}\end{array}$ & $\begin{array}{c}0.0285 \\
(0.0042)^{\star \star \star}\end{array}$ \\
\hline Friday & $\begin{array}{c}-0.0051 \\
(0.0013)^{\star \star \star}\end{array}$ & $\begin{array}{c}-0.0049 \\
(0.0013)^{\star \star \star}\end{array}$ & $\begin{array}{c}-0.0050 \\
(0.0013)^{\star \star \star}\end{array}$ & $\begin{array}{c}-0.0062 \\
(0.0015)^{\star \star \star}\end{array}$ & $\begin{array}{c}-0.0041 \\
(0.0014)^{\star \star \star}\end{array}$ \\
\hline Monday & & & & $\begin{array}{c}-0.0034 \\
(0.0013)^{\star \star}\end{array}$ & \\
\hline Tuesday & & & & $\begin{array}{l}-0.0015 \\
(0.0011)\end{array}$ & \\
\hline Thursday & & & & $\begin{array}{l}-0.0005 \\
(0.0012)\end{array}$ & \\
\hline Controls & & $x$ & $x$ & $x$ & $x$ \\
\hline Company Fixed Effects & & & $x$ & $x$ & $x$ \\
\hline Homogeneous Sample & & & & & $x$ \\
\hline $\mathbf{R}^{2}$ & 0.0002 & 0.0022 & 0.1020 & 0.1022 & 0.1155 \\
\hline $\mathbf{N}$ & $N=121381$ & $N=121381$ & $N=121381$ & $N=121381$ & $N=23822$ \\
\hline
\end{tabular}

Notes: Estimates from OLS regressions with robust standard errors are reported in each column. Standard errors adjusted for heteroskedasticity and clustered by day of announcement. Publicly traded stocks in CRSP are matched to earnings announcements recorded in Compustat and I/B/E/S from the beginning of 1995 until June 2004 . In event time, day 0 is the day of the earnings announcement. The cumulative abnormal return for each stock is the raw buy-and-hold return adjusted using the estimated beta from market model. The homogeneous sample refers to announcements by companies that announced earnings both on Friday and other weekdays at least ten percent of the time. The set of controls includes indicators for the year of announcement, the month of announcement, and the decile of a firm's market capitalization.

* significant at $10 \%$; ${ }^{* \star}$ significant at $5 \%$; ${ }^{* \star *}$ significant at $1 \%$ 
Appendix Table 1. Accuracy of the Imputed Date for Earnings Announcements

\begin{tabular}{|c|c|c|c|c|c|c|c|}
\hline $\begin{array}{l}\text { Number of Trading Days After } \\
\text { Imputed Date for the Actual } \\
\text { Announcement }\end{array}$ & -2 & -1 & 0 & 1 & 2 & Other & Total \\
\hline & \multicolumn{7}{|c|}{ Panel A: Years 1984 to 1988} \\
\hline Number of Imputed Friday & 0 & 38 & 59 & 18 & 0 & 3 & 118 \\
\hline Announcements & $0.0 \%$ & $32.2 \%$ & $50.0 \%$ & $15.3 \%$ & $0.0 \%$ & $2.5 \%$ & $100.0 \%$ \\
\hline Number of Imputed Non-Friday & 1 & 74 & 280 & 53 & 8 & 11 & 427 \\
\hline \multirow[t]{2}{*}{ Announcements } & $0.2 \%$ & $17.3 \%$ & $65.6 \%$ & $12.4 \%$ & $1.9 \%$ & $2.6 \%$ & $100.0 \%$ \\
\hline & \multicolumn{7}{|c|}{ Panel B: Years 1989 to 1994} \\
\hline Number of Imputed Friday & 0 & 15 & 232 & 139 & 6 & 0 & 392 \\
\hline Announcements & $0.0 \%$ & $3.8 \%$ & $59.2 \%$ & $35.5 \%$ & $1.5 \%$ & $0.0 \%$ & $100.0 \%$ \\
\hline Number of Imputed Non-Friday & 2 & 21 & 391 & 27 & 2 & 21 & 446 \\
\hline \multirow[t]{2}{*}{ Announcements } & $0.4 \%$ & $4.7 \%$ & $87.7 \%$ & $6.1 \%$ & $0.4 \%$ & $4.7 \%$ & $100.0 \%$ \\
\hline & \multicolumn{7}{|c|}{ Panel C: Years 1995 to 2004} \\
\hline Number of Imputed Friday & 0 & 16 & 632 & 11 & 0 & 1 & 660 \\
\hline Announcements & $0.0 \%$ & $2.4 \%$ & $95.8 \%$ & $1.7 \%$ & $0.0 \%$ & $0.2 \%$ & $100.0 \%$ \\
\hline Number of Imputed Non-Friday & 1 & 13 & 546 & 5 & 0 & 6 & 571 \\
\hline Announcements & $0.2 \%$ & $2.3 \%$ & $95.6 \%$ & $0.9 \%$ & $0.0 \%$ & $1.1 \%$ & $100.0 \%$ \\
\hline
\end{tabular}

Notes: Newswire searches using Lexis-Nexis provide the actual date for the earnings announcement. The imputed date for the earnings announcement is generated from the recorded announcement dates in Compustat and I/B/E/S using a simple algorithm. The algorithm is described in the text and is designed to maximize the match between imputed and actual dates in the sample of 2614 observations randomly selected for a newswire search. 
Appendix Table 2. Characteristics of Stocks Classified by Earnings Surprise Quantile and Day of Week

\begin{tabular}{|c|c|c|c|c|c|c|c|c|c|c|c|}
\hline & $\begin{array}{c}1 \\
\text { Low }\end{array}$ & 2 & 3 & 4 & 5 & $\begin{array}{c}6 \\
\text { Surprise }=0\end{array}$ & 7 & 8 & 9 & 10 & $\begin{array}{c}11 \\
\text { High }\end{array}$ \\
\hline & \multicolumn{11}{|c|}{ Panel A: Mean Cumulative Abnormal Return by Earning Surprise Quantile in Event Time From 0 to 1} \\
\hline Friday & $\begin{array}{l}-0.0315 \\
(0.0044)\end{array}$ & $\begin{array}{l}-0.0274 \\
(0.0031)\end{array}$ & $\begin{array}{l}-0.0186 \\
(0.0031)\end{array}$ & $\begin{array}{l}-0.0153 \\
(0.0025)\end{array}$ & $\begin{array}{l}-0.0103 \\
(0.0026)\end{array}$ & $\begin{array}{l}-0.0036 \\
(0.0022)\end{array}$ & $\begin{array}{c}0.0023 \\
(0.0023)\end{array}$ & $\begin{array}{c}0.0035 \\
(0.0024)\end{array}$ & $\begin{array}{c}0.0126 \\
(0.0025)\end{array}$ & $\begin{array}{c}0.0122 \\
(0.0023)\end{array}$ & $\begin{array}{c}0.0224 \\
(0.0029)\end{array}$ \\
\hline Other Days & $\begin{array}{l}-0.0366 \\
(0.0014)\end{array}$ & $\begin{array}{l}-0.0291 \\
(0.0011)\end{array}$ & $\begin{array}{l}-0.0208 \\
(0.0010)\end{array}$ & $\begin{array}{l}-0.0165 \\
(0.0009)\end{array}$ & $\begin{array}{l}-0.0136 \\
(0.0008)\end{array}$ & $\begin{array}{l}-0.0061 \\
(0.0006)\end{array}$ & $\begin{array}{c}0.0006 \\
(0.0006)\end{array}$ & $\begin{array}{c}0.0099 \\
(0.0007)\end{array}$ & $\begin{array}{c}0.0155 \\
(0.0007)\end{array}$ & $\begin{array}{c}0.0206 \\
(0.0007)\end{array}$ & $\begin{array}{c}0.0294 \\
(0.0009)\end{array}$ \\
\hline \multicolumn{12}{|c|}{ Panel B: Mean Cumulative Abnormal Return by Earning Surprise Quantile in Event Time From 2 to 75} \\
\hline Friday & $\begin{array}{l}-0.0517 \\
(0.0143)\end{array}$ & $\begin{array}{l}-0.0144 \\
(0.0120)\end{array}$ & $\begin{array}{c}0.0118 \\
(0.0115)\end{array}$ & $\begin{array}{c}0.0103 \\
(0.0115)\end{array}$ & $\begin{array}{c}0.0089 \\
(0.0115)\end{array}$ & $\begin{array}{l}-0.0151 \\
(0.0098)\end{array}$ & $\begin{array}{c}0.0052 \\
(0.0082)\end{array}$ & $\begin{array}{c}0.0348 \\
(0.0100)\end{array}$ & $\begin{array}{c}0.0247 \\
(0.0093)\end{array}$ & $\begin{array}{c}0.0341 \\
(0.0104)\end{array}$ & $\begin{array}{c}0.0420 \\
(0.0123)\end{array}$ \\
\hline Other Days & $\begin{array}{l}-0.0098 \\
(0.0057)\end{array}$ & $\begin{array}{l}-0.0014 \\
(0.0044)\end{array}$ & $\begin{array}{l}-0.0023 \\
(0.0039)\end{array}$ & $\begin{array}{l}-0.0072 \\
(0.0034)\end{array}$ & $\begin{array}{l}-0.0060 \\
(0.0030)\end{array}$ & $\begin{array}{c}0.0003 \\
(0.0023)\end{array}$ & $\begin{array}{c}0.0042 \\
(0.0022)\end{array}$ & $\begin{array}{c}0.0104 \\
(0.0024)\end{array}$ & $\begin{array}{c}0.0215 \\
(0.0025)\end{array}$ & $\begin{array}{c}0.0346 \\
(0.0027)\end{array}$ & $\begin{array}{c}0.0452 \\
(0.0036)\end{array}$ \\
\hline \multicolumn{12}{|c|}{ Panel C: Mean Cumulative Abnormal Return by Earning Surprise Quantile in Event Time From 0 to 75} \\
\hline Friday & $\begin{array}{l}-0.0827 \\
(0.0145)\end{array}$ & $\begin{array}{l}-0.0423 \\
(0.0121)\end{array}$ & $\begin{array}{l}-0.0057 \\
(0.0122)\end{array}$ & $\begin{array}{l}-0.0057 \\
(0.0112)\end{array}$ & $\begin{array}{c}0.0007 \\
(0.0120)\end{array}$ & $\begin{array}{l}-0.0163 \\
(0.0111)\end{array}$ & $\begin{array}{c}0.0081 \\
(0.0087)\end{array}$ & $\begin{array}{c}0.0390 \\
(0.0102)\end{array}$ & $\begin{array}{c}0.0384 \\
(0.0098)\end{array}$ & $\begin{array}{c}0.0493 \\
(0.0110)\end{array}$ & $\begin{array}{c}0.0661 \\
(0.0130)\end{array}$ \\
\hline Other Days & $\begin{array}{l}-0.0459 \\
(0.0057)\end{array}$ & $\begin{array}{l}-0.0307 \\
(0.0044)\end{array}$ & $\begin{array}{l}-0.0236 \\
(0.0040)\end{array}$ & $\begin{array}{l}-0.0236 \\
(0.0034)\end{array}$ & $\begin{array}{l}-0.0192 \\
(0.0031)\end{array}$ & $\begin{array}{l}-0.0052 \\
(0.0024)\end{array}$ & $\begin{array}{c}0.0058 \\
(0.0023)\end{array}$ & $\begin{array}{c}0.0214 \\
(0.0025)\end{array}$ & $\begin{array}{c}0.0388 \\
(0.0027)\end{array}$ & $\begin{array}{c}0.0579 \\
(0.0029)\end{array}$ & $\begin{array}{c}0.0798 \\
(0.0039)\end{array}$ \\
\hline \multicolumn{12}{|c|}{ Panel D: Mean Cumulative Abnormal Return by Earning Surprise Quantile in Event Time From -30 to -1} \\
\hline Friday & $\begin{array}{l}-0.0732 \\
(0.0094)\end{array}$ & $\begin{array}{l}-0.0229 \\
(0.0065)\end{array}$ & $\begin{array}{l}-0.0217 \\
(0.0071)\end{array}$ & $\begin{array}{c}0.0016 \\
(0.0071)\end{array}$ & $\begin{array}{l}-0.0014 \\
(0.0075)\end{array}$ & $\begin{array}{l}-0.0142 \\
(0.0052)\end{array}$ & $\begin{array}{c}0.0148 \\
(0.0058)\end{array}$ & $\begin{array}{c}0.0205 \\
(0.0056)\end{array}$ & $\begin{array}{c}0.0131 \\
(0.0059)\end{array}$ & $\begin{array}{c}0.0169 \\
(0.0061)\end{array}$ & $\begin{array}{c}0.0141 \\
(0.0071)\end{array}$ \\
\hline Other Days & $\begin{array}{l}-0.0701 \\
(0.0031)\end{array}$ & $\begin{array}{l}-0.0356 \\
(0.0026)\end{array}$ & $\begin{array}{l}-0.0129 \\
(0.0025)\end{array}$ & $\begin{array}{l}-0.0134 \\
(0.0021)\end{array}$ & $\begin{array}{c}0.0000 \\
(0.0020)\end{array}$ & $\begin{array}{l}-0.0059 \\
(0.0014)\end{array}$ & $\begin{array}{c}0.0261 \\
(0.0014)\end{array}$ & $\begin{array}{c}0.0222 \\
(0.0016)\end{array}$ & $\begin{array}{c}0.0252 \\
(0.0016)\end{array}$ & $\begin{array}{c}0.0248 \\
(0.0017)\end{array}$ & $\begin{array}{c}0.0225 \\
(0.0022)\end{array}$ \\
\hline \multicolumn{12}{|c|}{ Panel E: Mean Surprise by Earning Surprise Quantile } \\
\hline Friday & $\begin{array}{c}-0.056606 \\
718\end{array}$ & $\begin{array}{c}-0.006895 \\
654\end{array}$ & $\begin{array}{c}-0.002661 \\
518\end{array}$ & $\begin{array}{c}-0.001137 \\
509\end{array}$ & $\begin{array}{c}-0.000387 \\
395\end{array}$ & $\begin{array}{c}0.000000 \\
894\end{array}$ & $\begin{array}{c}0.000316 \\
521\end{array}$ & $\begin{array}{c}0.000735 \\
602\end{array}$ & $\begin{array}{c}0.001365 \\
579\end{array}$ & $\begin{array}{c}0.002827 \\
743\end{array}$ & $\begin{array}{c}0.015698 \\
854\end{array}$ \\
\hline Other Days & $\begin{array}{c}-0.049801 \\
6308\end{array}$ & $\begin{array}{c}-0.006934 \\
6290\end{array}$ & $\begin{array}{c}-0.002678 \\
6297\end{array}$ & $\begin{array}{c}-0.001112 \\
6299\end{array}$ & $\begin{array}{c}-0.000379 \\
6289\end{array}$ & $\begin{array}{c}0.000000 \\
17830\end{array}$ & $\begin{array}{c}0.000306 \\
13022\end{array}$ & $\begin{array}{c}0.000714 \\
13020\end{array}$ & $\begin{array}{c}0.001377 \\
13014\end{array}$ & $\begin{array}{c}0.002826 \\
13015\end{array}$ & $\begin{array}{c}0.014828 \\
13010\end{array}$ \\
\hline
\end{tabular}

